Research paper

\title{
Acylated sulfonamide adenosines as potent inhibitors of the adenylate-forming enzyme superfamily
}

\author{
Dries De Ruysscher ${ }^{a}$, Luping Pang ${ }^{\text {a, }}$, Steff De Graef ${ }^{b}$, Manesh Nautiyal ${ }^{\text {a }}$, Wim M. De Borggraeve ${ }^{c}$, Jef Rozenski ${ }^{\text {a }}$, \\ Sergei V. Strelkov ${ }^{\mathrm{b}}$, Stephen D. Weeks ${ }^{\mathrm{b}, 1}$, Arthur Van Aerschot ${ }^{\mathrm{a}, *, 1}$ \\ ${ }^{a}$ Medicinal Chemistry, KU Leuven, Herestraat 49 BOX 1030, 3000, Leuven, Belgium \\ b Biocrystallography, KU Leuven, Herestraat 49 BOX 822, 3000, Leuven, Belgium \\ ${ }^{c}$ Molecular Design and Synthesis, KU Leuven, Celestijnenlaan 200F BOX 2404, 3001, Leuven, Belgium
}

Keywords:

Adenylating enzymes

Aminoacyl-tRNA synthetases

Hydrolytically stable inhibitors

Eclipsed interactions

Homo-adenosine derivatives

\section{A B S T R A C T}

The superfamily of adenylate-forming enzymes all share a common chemistry. They activate a carboxylate group, on a specific substrate, by catalyzing the formation of a high energy mixed phosphoanhydride-linked nucleoside intermediate. Members of this diverse enzymatic family play key roles in a variety of metabolic pathways and therefore many have been regarded as drug targets. A generic approach to inhibit such enzymes is the use of non-hydrolysable sulfur-based bioisosteres of the adenylate intermediate. Here we compare the activity of compounds containing a sulfamoyl and sulfonamide linker respectively. An improved synthetic strategy was developed to generate inhibitors containing the latter that target isoleucyl- (IleRS) and seryl-tRNA synthetase (SerRS), two structurally distinct representatives of class I and II aminoacyl-tRNA synthetases (aaRSs). These enzymes attach their respective amino acid to its cognate tRNA and are indispensable for protein translation. Evaluation of the ability of the two similar isosteres to inhibit serRS revealed a remarkable difference, with an almost complete loss of activity for seryl-sulfonamide $\mathbf{1 5}$ (SerSoHA) compared to its sulfamoyl analogue (SerSA), while inhibition of IleRS was unaffected. To explain these observations, we have determined a $2.1 \AA$ crystal structure of Klebsiella pneumoniae SerRS in complex with SerSA. Using this structure as a template, modelling of $\mathbf{1 5}$ in the active site predicts an unfavorable eclipsed conformation. We extended the same modelling strategy to representative members of the whole adenylate-forming enzyme superfamily, and were able to disclose a new classification system for adenylating enzymes, based on their protein fold. The results suggest that, other than for the structural and functional orthologues of the class II aaRSs, the O to C substitution within the sulfur-sugar link should generally preserve the inhibitory potency.

\section{Introduction}

Adenylate-forming enzymes all catalyse the same reaction: the condensation between ATP and a weakly nucleophilic carboxylate group of a substrate molecule, with the concomitant release of a pyrophosphate byproduct. The resulting unstable acyl-AMP intermediate (Fig. 1A) can be converted into a carboxylic acid derivative as it readily reacts with common nucleophiles such as alcohols, thiols or amines, giving rise to esters, thioesters and amides respectively. The large superfamily of enzymes, functionally linked by this chemistry, are involved in a variety of essential cellular processes, that include but are not limited to nucleotide and enzyme co-factor biosynthesis, lipid catabolism, and the modification and aminoacylation of tRNAs

\footnotetext{
* Corresponding author.

Email address: arthur.vanaerschot@kuleuven.be (A. Van Aerschot)

${ }^{1}$ Both authors equally supervised and gave guidance to this work.
}

necessary for protein translation [1]. The critical roles of these enzymes have stimulated considerable interest in targeting them for the development of new antimicrobials [2,3].

Despite the common chemistry these enzymes share, they can be divided into five structurally distinct classes (Fig. 2). While a previously reported classification system employed a mixture of structural and functional similarity to make such divisions [1], we have updated this to account for newly available X-ray crystallographic structures and separated the clusters purely based on their protein fold. Class I members inherit their grouping as a result of older nomenclature in the literature for the main representatives of this group, the HIGH-motif containing Class I aminoacyl-tRNA synthetases (aaRS) $[4,5]$. Furthermore, this class also includes enzymes belonging to the N-type ATP pyrophosphatase family, such as GMP and NAD synthetase [6]. Both enzyme families are part of a larger functionally diverse group collectively known as the HUP family (CATH 3.40.50.620 [7]). Similar to the first class, the previously annotated Class II aminoacyl-tRNA synthetases designate the numbering of the 
<smiles>[R]C(=O)OP(=O)([O-])OC[C@H]1O[C@@H](n2cnc3c(N)ncnc32)[C@H](O)[C@@H]1O</smiles>

C

Acyl-AMP (active intermediate)<smiles>[R]C([NH3+])C(=O)N1CCC[C@]2(CO)O[C@H](n3cnc4c(N)ncnc43)[C@H](O)[C@@H](O)[C@H]2O1</smiles>

aaSoA

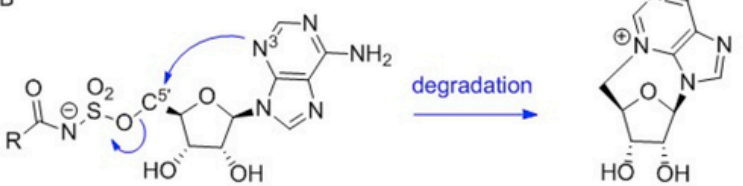

High affinity acyl-SA

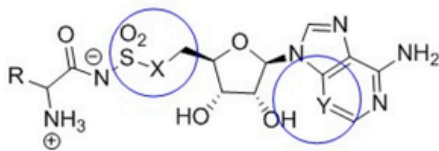

aaS3DA $(X=O, Y=C)$ aaSoHA $(X=C, Y=N)$
$N$-cycloadenosine

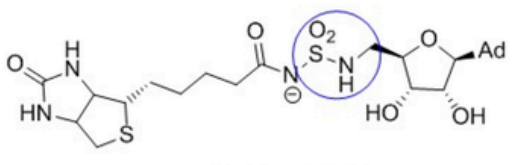

Biotinoyl-AMS

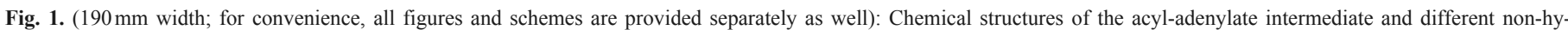

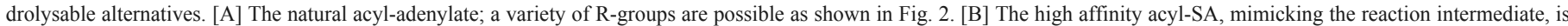

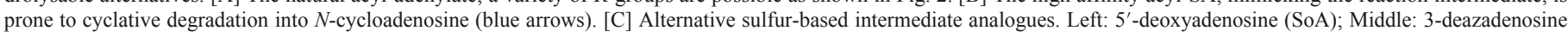

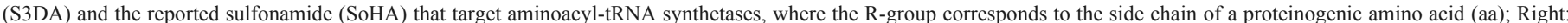

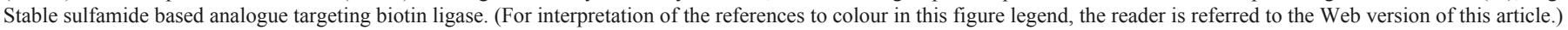

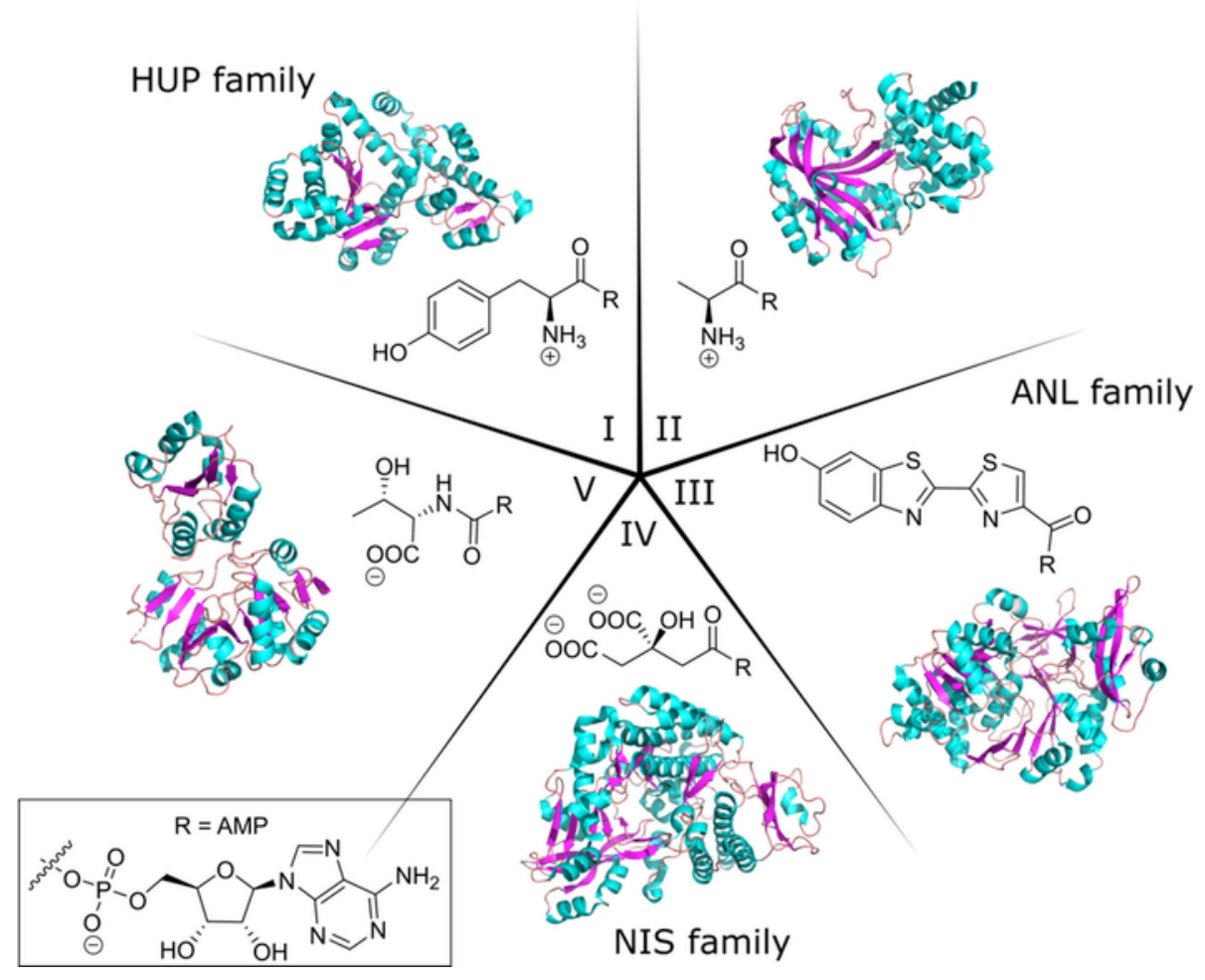

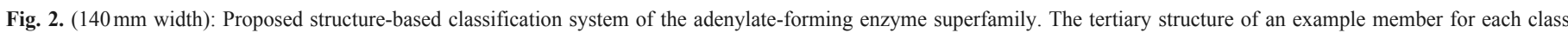

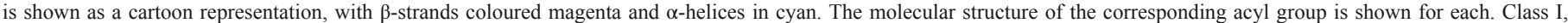

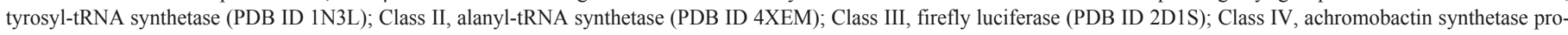

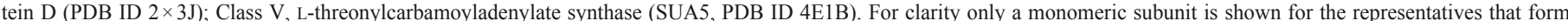
higher-order oligomers. (For interpretation of the references to colour in this figure legend, the reader is referred to the Web version of this article.)

second structural cluster (CATH 3.30.930.10 [4,5], Fig. 2). This family also includes biotin and lipoate ligases that attach their respective substrate to protein targets [8]. Members of the Class III cluster (originally termed Class I in the older classification scheme [1]) are part of the functionally diverse ANL family (CATH 3.40.50.980 [9]). This family includes acetyl-CoA synthetase, fatty acid ligase and the non-ribosomal peptide synthetases (NRPS). Class IV adenylate-forming enzymes encompass the NRPS-independent peptide (NIS) synthetases involved in siderophore biosynthesis [10]. Finally, the Class
V group contains enzymes that transfer an activated carbamoyl moiety, which is necessary in some antibiotic biosynthetic pathways as well as for the formation of the universal $\mathrm{N}^{6}$-threonylcarbamoyl adenosine tRNA modification [11].

In general, mimicking the acyl-AMP intermediates by hydrolytically stable competitive inhibitors has proven a potent way of targeting the adenylate-forming enzymes from the different structural classes [12-14]. Focusing on aaRSs, enzymes which catalyse the activation and esterification of amino acids to their cognate tRNA, there 
have been many successful approaches to enhance the stability of the aminoacyl-adenylate intermediate by substitution of the mixed phosphoanhydride linker with a sulfur based isoster [15-18]. Amongst these the aminoacyl-sulfamate isosteres (Fig. 1B, where R is a decarboxylated amino acid) have been established as the most potent aaRS inhibitors during the last two decades, but further elaboration of this scaffold to improve uptake has been limited as the sulfamate linker is prone to $N$-cycloadenosine formation (Fig. 1B) [12]. Numerous attempts have been made to improve the stability of these isosteres. Our group deleted the $5^{\prime}$-oxygen atom resulting in aaSoA analogues (Fig. 1C, aaSoA) [19]. This leads to a less electrophilic 5'-carbon atom because the resulting sulfonamide moiety is a poorer leaving group compared to the sulfamoyl group. Unfortunately, the majority of the resulting compounds no longer efficiently inhibited their target aaRS. More recently, we applied another strategy involving the synthesis of 3-deazaadenosine analogues (Fig. 1C, aaS3DA). These compounds lack the $\mathrm{N}^{3}$ atom of the adenine base, which is responsible for the nucleophilic attack on the $5^{\prime}$-carbon atom. An evaluation of six different analogues highlighted a specific class dependent inhibitory activity [20].

Alternative stabilization strategies have been applied to sulfamate based acyl-AMP bioisosteres targeting other adenylate-forming enzymes. In an attempt to limit disproportionation of biotinoyl-sulfamoyladenosine, a potent inhibitor of the Class II member biotin ligase, modifications of the adenine base [12] or addition of a methyl group to the C5'-position of the ribose [13] resulted in stabilization of the compounds. This was rationalized as likely the result of steric hindrance, preventing the syn-conformation required for the adenine $\mathrm{N} 3$ attack on the $\mathrm{C} 5^{\prime}$ atom. In both cases the modifications had a minimal effect on binding affinity, but the base modifications dramatically reduced the activity on whole cells [12]. In addition to these scaffold elaborations, attempts have been made to substitute the 5 '-oxygen with alternative atoms [12,21]. Substitution with an amine, yielding biotinoyl-AMS resulted in a more stable compound that is a potent and selective antitubercular [12]. Although chemically more difficult, replacement of the same atom with a methylene group also resulted in a potent inhibitor that was resistant to chemical and biochemical induced degradation $[12,13]$.

The reported stability and effectiveness of the adenosine sulfonamide scaffold raises an open question as to whether it can be applied to other adenylate-forming enzymes. We developed an improved synthetic strategy to generate two aminoacyl analogues (Fig. 1C, aaSoHA) targeting the Class I isoleucyl-tRNA synthetase (IleRS) and the Class II seryl-tRNA synthetase (SerRS). Following synthesis of IleSoHA 14 and SerSoHA 15 (Scheme 1), the activity against the corresponding enzymes was evaluated. Combined with X-ray crystallographic studies and modelling we extended this characterization to representatives of each class of the adenylate-forming enzyme superfamily.

\section{Results}

\subsection{Synthesis of aminoacylated sulfonamide homo-adenosines (aaSoHAs)}

Reagents and conditions: [A] (a) DMP, PTSA $\cdot \mathrm{H}_{2} \mathrm{O}$, acetone, rt, overnight; (b) TBDMS-Cl, imidazole, anh. DMF, rt, $3 \mathrm{~d}$; (c) $\mathrm{Boc}_{2} \mathrm{O}$, DMAP, TEA, anh. DMF, $0^{\circ} \mathrm{C}$ - rt, $3 \mathrm{~d}$; (d) TBAF $3 \mathrm{H}_{2} \mathrm{O}$, anh. THF, rt, overnight; (e) Dess-Martin periodinane, anh. DCM, rt, $1.5 \mathrm{~h}$; (f) (1) 9, LiHMDS, anh. DMF/THF, $-78^{\circ} \mathrm{C}, 2.5 \mathrm{~h}$; (2) 6, anh. THF, $-78^{\circ} \mathrm{C}-\mathrm{rt}$, $2 \mathrm{~d}$; (g) $\mathrm{H}_{2}, \mathrm{Pd} / \mathrm{C}$, anh. $\mathrm{MeOH}, \mathrm{rt}, 3 \mathrm{~d}$; (h) TFA, anh. DCM, $0^{\circ} \mathrm{C}, 2 \mathrm{~h}$; (i) Boc-aa-(Bn)-OSu, $\mathrm{Cs}_{2} \mathrm{CO}_{3}$, anh. DMF, $0^{\circ} \mathrm{C}-\mathrm{rt}, 2 \mathrm{~d}-4 \mathrm{~d}$; (j) $\mathrm{H}_{2}$,<smiles>CC(C)(C)[13C](=O)c1ccccc1</smiles>

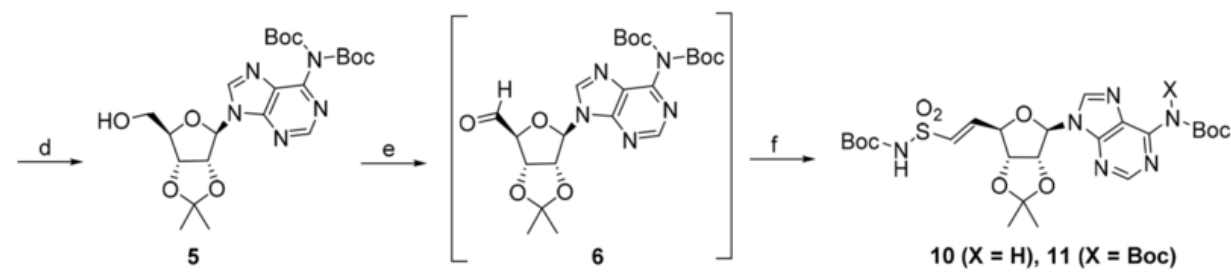

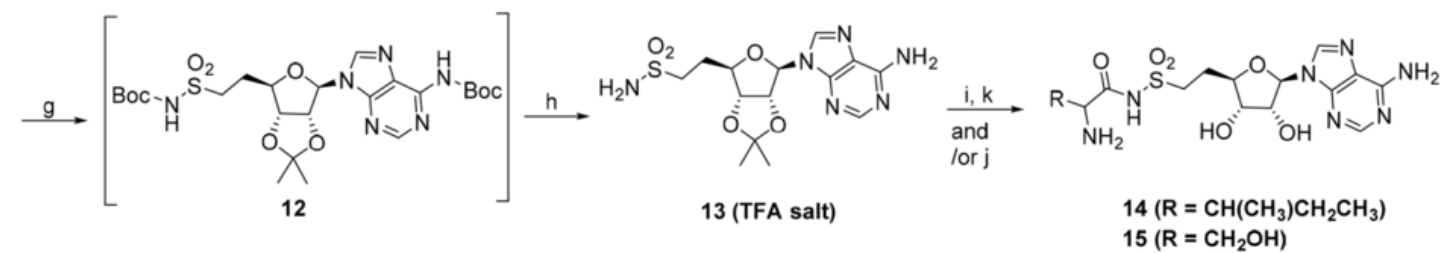

[B]

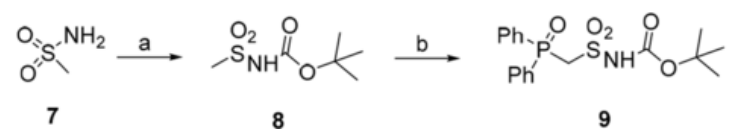


$\mathrm{Pd} / \mathrm{C}$, anh. $\mathrm{MeOH}, \mathrm{rt}, 2 \mathrm{~d}$; (k) TFA $/ \mathrm{H}_{2} \mathrm{O}, 0^{\circ} \mathrm{C}$ - rt, $3 \mathrm{~h}$; [B] (a) $\mathrm{Boc}_{2} \mathrm{O}$, DMAP, TEA, anh. DCM, $0^{\circ} \mathrm{C}$ - rt, overnight; (b) (1) $(i \operatorname{Pr})_{2} \mathrm{NH}$, $n$-BuLi, anh. THF, $-78^{\circ} \mathrm{C}-0^{\circ} \mathrm{C}, 1 \mathrm{~min}$; (2) 8, anh. THF, $-78^{\circ} \mathrm{C}$, 10 min; (3) $\mathrm{Ph}_{2} \mathrm{P}(\mathrm{O}) \mathrm{Cl},-78^{\circ} \mathrm{C}, 1.5 \mathrm{~h}$.

The synthetic scheme for the desired compounds 14 and 15 (Scheme 1A) started with selective introduction of the isopropylidene moiety. TBDMS protection of the remaining primary alcohol and subsequent di-Boc protection of the heterocyclic amine gave compound 4. Selective deprotection of the silyl moiety resulted in protected nucleoside 5. In analogy with the work of Shi et al., $\mathbf{5}$ was used in a Wittig-Horner reaction which, in our hands, afforded only $\mathbf{1 0}$ with a yield of $23 \%$ [12]. In spite of several attempts, we could not reproduce the previously published results whereby only $\mathbf{1 1}$ was obtained with a better yield than what we achieved for 10. The employed Wittig-Horner reagent 9 was synthesized, utilizing methanesulfonamide 7 as the starting material in which the amino group was first Boc protected (Scheme 1B). The di-anion of $\mathbf{8}$ was then prepared with freshly made LDA, whereafter it was treated with diphenylphosphinic chloride in a substitution reaction (Scheme 1B). An important issue in this Wittig-Horner reaction was the instability of aldehyde 6 (Scheme 1A). This compound was synthesized in a high (isolated) yield (88\%) utilizing Dess-Martin periodinane, but could not be stored overnight. Degradation of $\mathbf{6}$ was confirmed by NMR analysis and as a consequence, the crude aldehyde had to be used immediately upon production in order to obtain 10. In addition, we observed that the selective $(E)$-alkene forming reaction limited the amount of starting material 5 which can be used, because attempts to scale-up $(0.5 \mathrm{~g})$ in our hands no longer afforded the desired product 10. Quantitative reduction of the double bond using hydrogen gas resulted in com- pound 12, which was confirmed by mass analysis. Hence, 12 was immediately deprotected under anhydrous acidic conditions. Unfortunately, the desired compound $\mathbf{1 3}$ in our hands decomposed during work-up, in contrast to previously reported literature [12].

To avoid the use of a Boc protecting group on the sulfonamide moiety, we chose to prepare Wadsworth-Horner-Emmons and Wittig-Horner compounds $\mathbf{1 6}$ and $\mathbf{1 8}$ respectively (Scheme 2) in a similar reaction sequence as described for Boc protected Wittig-Horner product 9 (Scheme 1B). Both benzhydryl (16) and $\mathrm{Cbz}$ (18) protecting groups can be removed upon hydrogenolysis, thus avoiding the use of acid. Compounds 16 and 18 were both utilized for the $\mathrm{C}-\mathrm{C}$ coupling reaction with crude aldehyde $\mathbf{6}$, but both reactions failed to give the desired products $\mathbf{1 7}$ or $\mathbf{1 9}$ respectively (Scheme 2). The reaction of $\mathbf{6}$ with 16 resulted in the formation of two unknown (and incorrect) compounds, while reaction of $\mathbf{6}$ with $\mathbf{1 8}$ unexpectedly caused a Boc transfer from the adenine base to the sugar part of $\mathbf{5}$, resulting in protected 5'-O-Boc-adenosine.

Reagents and conditions: (a) (1) DMAP, $\mathrm{SOCl}_{2}$, anh. $\mathrm{MeCN}, 0^{\circ} \mathrm{C}$ - rt, 4 h; (2) anh. MeCN, rt, overnight; (b) $\mathrm{Boc}_{2} \mathrm{O}$, DMAP, TEA, anh. $\mathrm{MeCN}, 0{ }^{\circ} \mathrm{C}-\mathrm{rt}, 3 \mathrm{~d}$; (c) $(1)(i \operatorname{Pr})_{2} \mathrm{NH}, n$-BuLi, anh. THF, $-78^{\circ} \mathrm{C}$ - $0^{\circ} \mathrm{C}, 1 \mathrm{~min}$; (2) $N$-benzhydrylmethanesulfonamide, anh. DMF, $-78^{\circ} \mathrm{C}, 1 \mathrm{~h}$; (3) 21, anh. DMF, $-78^{\circ} \mathrm{C}, 1 \mathrm{~h}$; (4) anh. DMF/THF, $-78^{\circ} \mathrm{C}$ $-\mathrm{rt}, 3 \mathrm{~d}$.

A different approach for these modified Wittig reactions had to be found for obtaining the $\mathrm{C}-\mathrm{C}$ linked molecules. Therefore, a nucleophilic substitution was envisioned in order to extend the $5^{\prime}$-carbon side chain (Scheme 3). Hereto, the remaining alcohol group of $\mathbf{2}$ was substituted by a chlorine atom, using thionyl chloride as the halogen donor. Chlorine would act as a stable, but still good leaving group
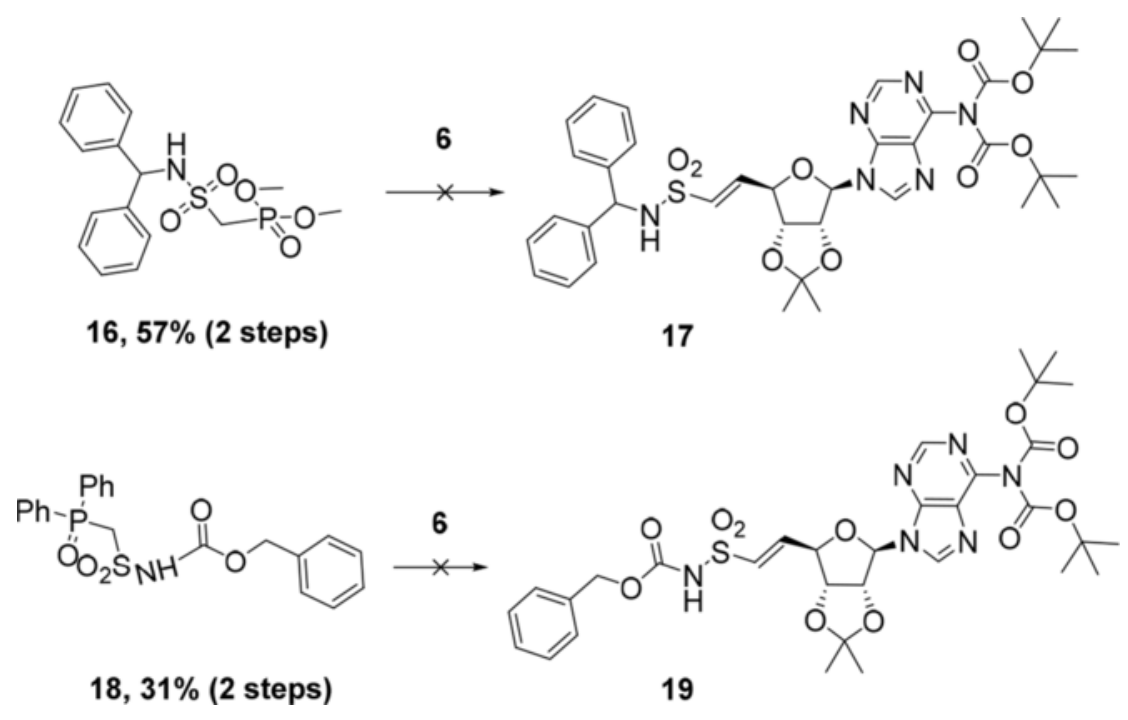

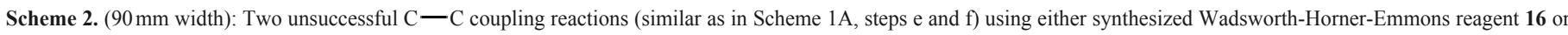
Wittig-Horner compound $\mathbf{1 8}$ (similar as in Scheme 1B).

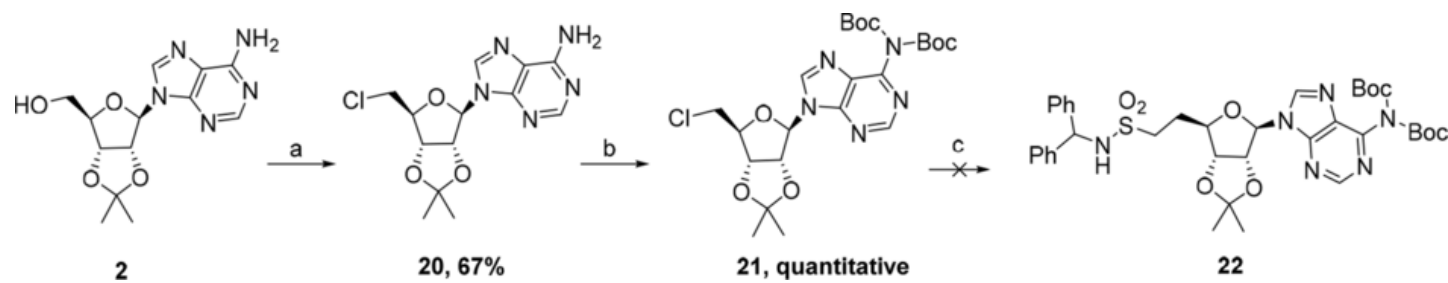

Scheme 3. (190 mm width): Unsuccessful nucleophilic substitution approach which would have resulted in the desired sulfonamide 22. 
(installing better leaving groups immediately results in the formation of $N$-cycloadenosine (Fig. 1A), as seen with the sulfamate analogues of 14 and 15). The adenine base was then di-Boc protected to obtain 21 devoid of acidic protons. This compound was subsequently reacted with the di-anion of $N$-benzhydrylmethanesulfonamide, which should lead to sulfonamide 22. Unfortunately, no reaction occurred, even at room temperature, while at elevated temperatures, decomposition of the nucleoside was observed.

In view of decomposition of nucleosides at elevated temperatures in acidic medium, prior to work-up, the mixture, as obtained in step $\mathrm{h}$ of Scheme 1, was neutralized immediately following reaction with an excess of bicarbonate. Following conventional purification, $\mathbf{1 3}$ was isolated as its TFA salt in moderate yield. Amino acids isoleucine and serine were then coupled to the sulfonamide moiety using $\mathrm{Cs}_{2} \mathrm{CO}_{3}$. Following removal of all remaining protecting groups, crude products 14 and 15 were purified by preparative reversed-phase HPLC, resulting in the desired analogues IleSoHA 14 and SerSoHA 15.

\subsection{Inhibitory activity}

The ability of $\mathbf{1 4}$ and $\mathbf{1 5}$ to inhibit the respective aaRS was evaluated using an in vitro aminoacylation assay, monitoring their effect on the transfer of the appropriate $\mathrm{C}^{14}$ radiolabelled amino acid to tRNA (Fig. 3). In both cases the purified recombinant $E$. coli protein was utilized with a total tRNA pool from the same organism. Compound $\mathbf{1 4}$ showed potent inhibitory potential for the target $E$. coli IleRS. The inhibition profile, including the steep increase in aaRS activity between 50 and $10 \mathrm{nM}$ of the compound, is in line with previous studies of the sulfamoyl analogue [20]. This observation is also reflected in an even slightly improved apparent $\mathrm{K}_{\mathrm{i}}$ value of $1.2 \mathrm{nM}$ for $\mathbf{1 4}$ (Supplemental Fig. S1) compared to its sulfamoyl analogue $\left(\mathrm{K}_{\mathrm{i}, \mathrm{app}}=1.9 \mathrm{nM}\right.$ [20]). Surprisingly, 15 demonstrated little inhibitory activity. At a final concentration of $2 \mu \mathrm{M}$, it only reduced the ability of E. coli SerRS to aminoacylate tRNA by $30 \%$. This is more than a 200 -fold reduction in inhibitory capacity when compared to $\mathbf{1 4}$, and a marked reduction to the previously reported activity of the analogous sulfamoyl, which showed an apparent $\mathrm{K}_{\mathrm{i}}$ of $0.18 \mathrm{nM}$ [20].

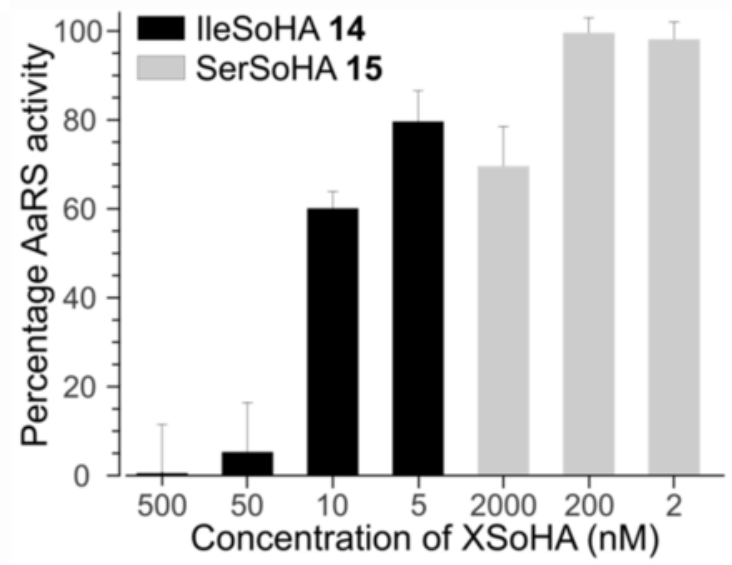

Fig. 3. ( $90 \mathrm{~mm}$ width): Aminoacylation activity of $E$. coli ileRS and serRS in the presence of the respective sulfonamide linked intermediate analogue. Values were normalized based on the measured activity of each enzyme in the absence of inhibitor. Experiments were performed in triplicate, the mean and standard error are presented.

\subsection{Structural studies}

To understand why SerSoHA 15 showed a dramatically reduced activity relative to $\mathbf{1 4}$, we solved the X-ray crystallographic structure of Klebsiella pneumoniae SerRS (KpSerRS) in complex with the canonical SerSA analogue (Fig. 4A and Supplemental Table 1). Examination of datasets of similar crystals soaked with high concentrations of $\mathbf{1 5}$ failed to reveal any suitable electron density corresponding to the compound (data not shown). KpSerRS shares $93.7 \%$ sequence identity $(97.4 \%$ similarity) with the E. coli homologue, therefore interpretation of the ligand bound structure can be compared to the in vitro studies with the latter enzyme. The asymmetric unit of the crystal contains one protomer of the dimeric enzyme (Fig. 4A), the canonical homodimer formed by a crystallographic 2 -fold rotation axis. The KpSerRS structure shows high similarity to the homologous enzyme from other bacterial species [22,23], with an N-terminal antiparallel coiled-coil arm, involved in tRNA binding, and a mixed $\alpha / \beta$ catalytic domain (Fig. 4A and Supplemental Fig. S2). The $2.1 \AA$ crystal structure, currently the highest resolution for a bacterial SerRS orthologue in the PDB, unambiguously reveals the conformation of the intermediate analogue as evidenced by the polder.omit map (Fig. 4A, insert). The compound makes numerous interactions with the protein, showing high complementarity with the large active site. Careful examination of the $5^{\prime}$-oxygen atom suggests it only makes weak Van der Waals interactions with the sidechain NH1 and NH2 atoms of Arg268. This residue, which is part of the catalytic core, is found in all Class II aaRSs where it anchors the N-terminal side of a conserved sequence motif $[5,20]$. In the ligand bound structure Arg268 makes H-bond and salt bridge interactions with the sulfamoyl and carbonyl group of the intermediate analogue (Fig. 4B). The latter is mediated by a strong ionic interaction as the tautomer of conjugated peptide bond, with an estimated pKa of 3.1 using Schrodinger Epik software [24], will be deprotonated at physiological $\mathrm{pH}$. This calculated value is comparable to what was determined in previous literature for equivalent molecules [25]. In the case of $\mathbf{1 5}$, calculations suggest a slight increase in the $\mathrm{pKa}$ of this group to 4.1 , therefore it is also predicted to be deprotonated under the native conditions that were evaluated and therefore is likely not the cause of the observed loss of activity.

Using the empirically determined structure, SerSoHA 15 was modelled in the enzyme active site maintaining the same conformation of SerSA. The substitution of the $\mathrm{O}^{\prime}$ atom with a methylene group is readily accommodated, with no inter- or intramolecular clashes. Maintaining a torsional angle of $127.8^{\circ}$ between the $\mathrm{C} 4^{\prime}$ atom and the sulfone group, the minimised model shows that the additional protons introduced by the methylene substitution are found in an energetically unfavorable (nearly) eclipsed position (Fig. 4C). To start with, a torsional angle of $13^{\circ}$ is observed between the $\mathrm{C}^{\prime}$ and $\mathrm{C}^{\prime}$ protons (Fig. $4 \mathrm{C}$, insert). Secondly, the other $\mathrm{C} 6^{\prime}$ proton is offset from the $\mathrm{C}^{\prime}{ }^{\prime}-\mathrm{C} 5^{\prime}$ bond by a $16^{\circ}$ torsional angle. Finally, a similar torsional angle of $19^{\circ}$ is seen between the second $\mathrm{C} 5^{\prime}$ proton and the $\mathrm{C} 6^{\prime}-\mathrm{S}$ bond, a near overlap of atoms that is also observed in the experimental SerSA bound structure between the $\mathrm{C} 5^{\prime}$ proton and the $\mathrm{O}^{\prime}-\mathrm{S}$ bond. Hence this structural pose of SerSoHA 15 is energetically unfavorable.

\subsection{Comparative modelling studies}

As IleSoHA 14 demonstrated high affinity for its target aaRS (Fig. 3 ), we wanted to examine whether the conformation of the atoms around the $\mathrm{C} 5^{\prime}-\mathrm{C}^{\prime}$ bond of this compound was similar to that ob- 
A

B

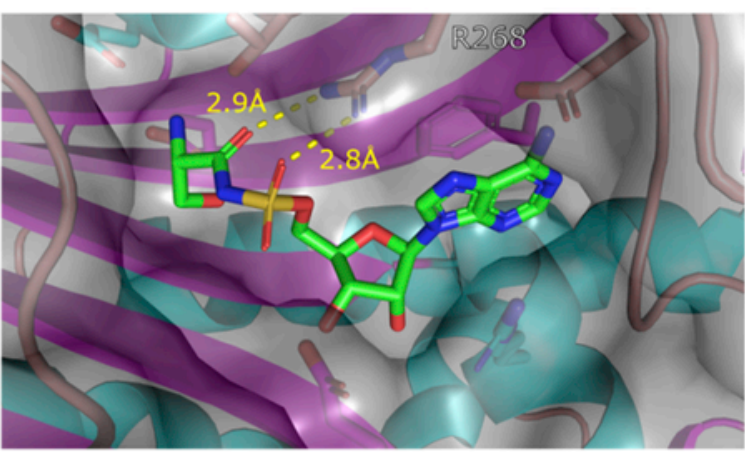

C

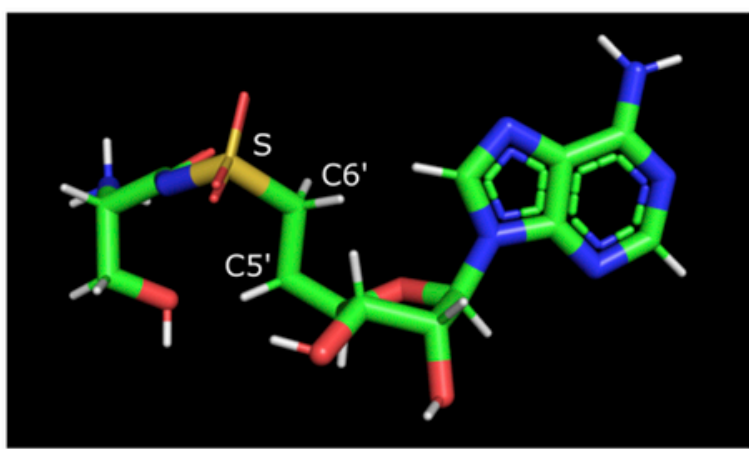

$\downarrow 90^{\circ}$

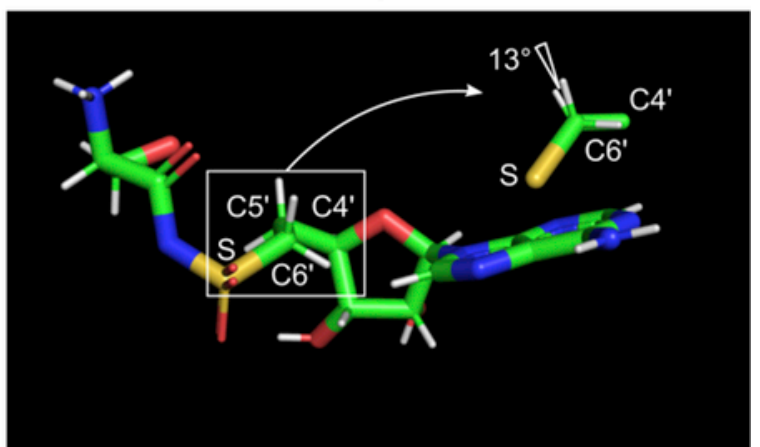

Fig. 4. ( $90 \mathrm{~mm}$ width): (A) The crystal structure of $K$. pneumoniae SerRS bound to the intermediate analogue SerSA (PDB ID $6 \mathrm{H} 9 \mathrm{X}$ ). The protein is depicted as a cartoon representation and the SerSA shown as spheres. The insert shows the phenix.polder omit map for the bound SerSA contoured at $6 \sigma$. (B) Complementarity of SerSA with the enzyme active site. The protein surface has been calculated using a $1.4 \AA$ probe. The side chains of interacting residues are shown as stick representations, the carbon atoms are coloured based on the secondary structure in panel A. R268 interacts with the carbonyl and sulfamate oxygen atoms of SerSA (yellow dashed lines). (C) Model of SerSoHA 15 based on the pose of SerSA, showing the 3'-endo ribose conformation and the eclipsing protons and bonds. The insert shows the torsional angle between the eclipsed $\mathrm{C}^{\prime}$ and $\mathrm{C}^{\prime}$ protons when looking down the $\mathrm{C}^{\prime}-\mathrm{C} 5^{\prime}$ bond. The predicted protonation state at physiological $\mathrm{pH}$ is shown. (For interpretation of the references to colour in this figure legend, the reader is referred to the Web version of this article.)

served for SerSoHA 15 bound to SerRS. As there are no high resolution (sub $2.5 \AA$ ) crystal structures of IleRS in complex with an aminoacyl-AMP intermediate, or analogues thereof, we used the $1.85 \AA$ resolution structure of the related leucyl-tRNA synthetase (LeuRS) in complex with LeuSA for comparative analysis (Fig. 5A; PDB ID 2V0C). Using a re-refined structure of this protein-ligand complex LeuSoHA was modelled in the active site, by substituting the O5' atom of LeuSA with a methylene group whilst maintaining the same bound conformation (Fig. 5B). In the original LeuSA structure one of the oxygen atoms of the sulfamoyl group makes a H-bond with a backbone atom which is maintained in the LeuSoHA model. Further examination of the model shows no clashing atoms between the compound and the protein suggesting this pose is a viable conformation. Focusing on the intramolecular contacts of LeuSoHA a staggered relationship for the $\mathrm{C}^{\prime}$ and $\mathrm{C}^{\prime}$ protons (torsional angle of $42^{\circ}$ ) was observed (Fig. 5B, insert). Similar values were also observed between the other $\mathrm{C} 5^{\prime}$ proton and the $\mathrm{C} 6^{\prime}-\mathrm{S}$ bond (torsional angle of $51^{\circ}$ ). The second $\mathrm{C}^{\prime}$ proton and the $\mathrm{C}^{\prime}-\mathrm{C}^{\prime}$ bond exhibited a torsional angle of $35^{\circ}$.

In order to investigate if we can extrapolate the above analyses of LeuSoHA and SerSoHA 15 to all other Class I and Class II aaRSs respectively, we examined the available intermediate-bound or non-hydrolysable analogue-bound crystal structures of the different aaRS orthologues (Fig. 5C and D). The ligands in the Class I representatives were superposed using the $\mathrm{C}^{\prime}, \mathrm{C}^{\prime}$ ' and $\mathrm{O}^{\prime}$ ' atoms of the ribose, which all demonstrated the same $2^{\prime}$-endo pucker (Fig. 5C). It is clear from this overlap that the position of the sulfamate group and the adenine ring is not completely fixed between enzymes. Rotating around the base N9 atom, the angle between the most displaced adenine rings is $16^{\circ}$, resulting in a maximum distance of $1.98 \AA$ between their distal ends. Similarly, with a mean value of $161.6^{\circ}$ but a standard deviation of $13.7^{\circ}$, the torsion angle between the $\mathrm{C} 4^{\prime}-\mathrm{C} 5^{\prime}$ and the $\mathrm{C} 6^{\prime}-\mathrm{S}$ bonds also demonstrate some variability. In all cases though the staggered conformation of the atoms circling the $\mathrm{C}^{\prime}-\mathrm{C}^{\prime}$ bond is maintained, suggesting that the $\mathrm{O}^{\prime}$ to $\mathrm{C}$ substitution will not result in a detrimental effect on binding of the inhibitor to any Class I aaRS. The same ring based superposition strategy was also applied to all available Class II bound ligands, each showing the same 3'-endo ribose pucker (Fig. 5D). The overall conformation of the Class II inhibitors is more strictly fixed, with an all non-H atom RMSD of $0.417 \AA$. In particular the torsion angle between the $\mathrm{C} 4^{\prime}-\mathrm{C} 5^{\prime}$ and the $\mathrm{C} 6^{\prime}-\mathrm{S}$ bonds, with a mean value of $127.4^{\circ}$, has a standard deviation of $7.5^{\circ}$ - just over half that was observed for the Class I intermediate analogues. This strongly suggests that the energetically unfavorable conformation observed for the SerSoHA model would be replicated with an $\mathrm{O}^{\prime}$ to $\mathrm{C}$ substitution in each of the examined structures, likely negatively affecting the binding affinity of all Class II aaRS targeting sulfonamide-linked intermediate analogues.

As the two aaRS classes are members of a larger superfamily of adenylate-forming enzymes (Fig. 2), we extended our structural analyses to other representatives, to evaluate whether the acyl-sulfonamide linker strategy can be employed to this structurally and functionally diverse group of enzymes (Fig. 6). A search for suitable ligand bound crystal structures, specifically of enzymes that have been previously considered as druggable targets, was performed. In all cases the $\mathrm{O}^{\prime}$ of the acyl-SA intermediate analogue was replaced by a methylene group in the minimised structure. For the Class I 


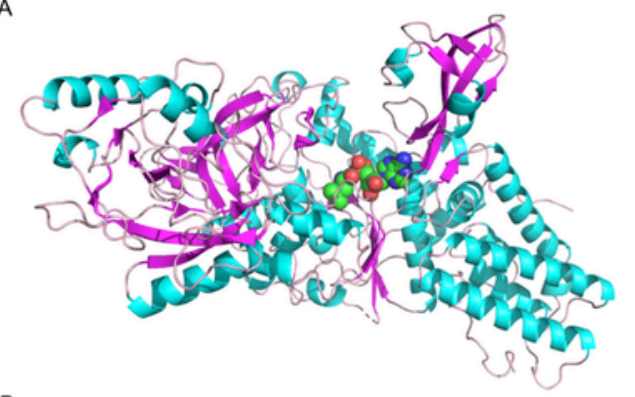

B
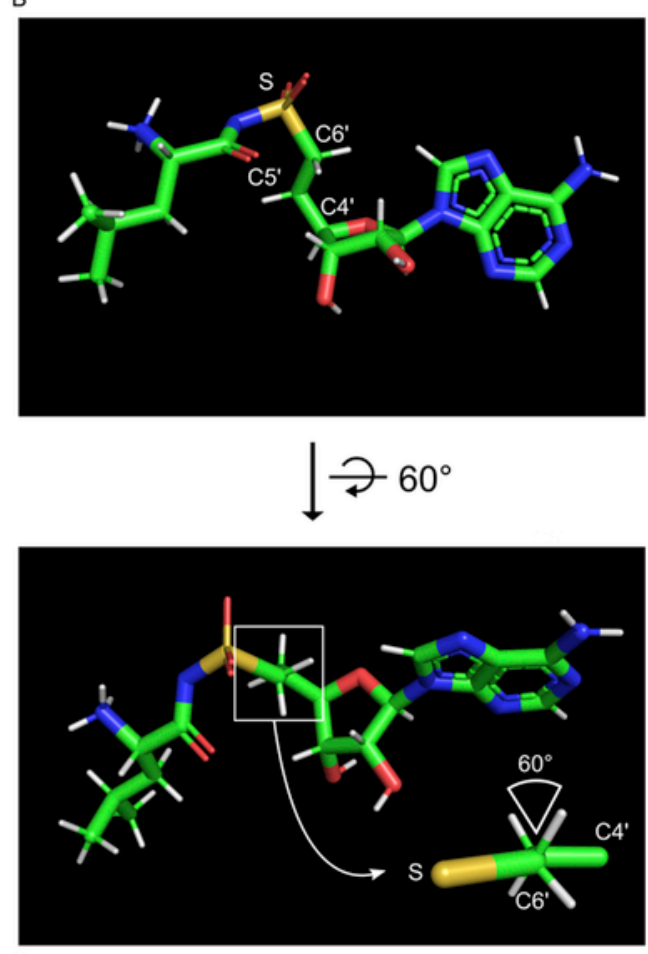

C
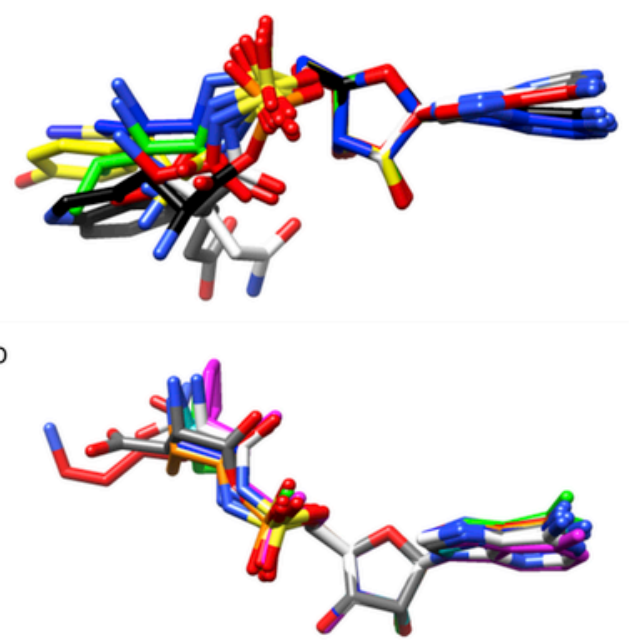

Fig. 5. (90 mm width): [A] Structure of re-refined T. thermophilus LeuRS, shown as a cartoon representation, bound to leucyl-sulfamoyl-adenosine (LeuSA - green spheres); [B] Stick representation of the bound pose of LeuSA. The insert in the lower panel shows the torsional angle between the staggered C5' and C6' protons when looking down the $\mathrm{C6}^{\prime}-\mathrm{C5}^{\prime}$ bond. The predicted protonation state at physiological $\mathrm{pH}$ is shown: [C] Superposition of class I aaRS intermediate analogues, making use of the available ligand bound structures for IleRS (PDB ID 1JZQ - red), TyrRS (PDB ID 6I5Y-yellow), LeuRS (PDB ID 2V0C - green), MetRS (PDB ID 1PFY-blue), GlnRS (PDB ID 1QTQ - white), GluRS (PDB ID 3AFH- grey) and TrpRS (PDB ID 1I6K black); [D] Overlap of the bound intermediate analogues of class II aaRS representatives LysRS (PDB ID 3E9H - red), SerRS (PDB ID 6H9X - green), ProRS (PDB ID 2J3L - magenta), ThrRS (PDB ID 1NYQ- cyan), GlyRS (PDB ID 5F5W-blue), As$n R S$ (PDB ID 1X55- white), AspRS (PDB ID 1G51-grey) and AlaRS (PDB ID 3HXZorange). The stated colors correspond to the carbon atoms. (For interpretation of the references to colour in this figure legend, the reader is referred to the Web version of this article.)

$\mathrm{NAD}+$ synthetase, a member of the N-type ATP pyrophosphatase family, the conformation of the acyl-adenylate analogue is distinct to that observed for the Class I aaRS (1KQP, Fig. 6A). These variances include the pucker of the ribose and the position of the adenine relative to the sugar, and reflect differences in the binding mode between these two class members. Despite this, the sulfonamide based analogue of the NAD + -adenylate intermediate displays a staggered conformation with a $164^{\circ}$ torsion angle between the $\mathrm{C}^{\prime}-\mathrm{C} 5^{\prime}$ and $\mathrm{C} 6^{\prime}-\mathrm{S}$ bonds, close to the mean value seen for the Class I tRNA synthetases. This positioning of the sulfonamide group within the active site, relative to the ribose, results in a $50^{\circ}$ offset between the $\mathrm{C}^{\prime}$ and $\mathrm{C}^{\prime} \mathrm{H}$-atoms (Fig. 6A)

A biotinoyl-SoHA intermediate analogue, targeting the alternative Class II member biotin-protein ligase BirA (Fig. 6B), has previously been described as a potent inhibitor of this enzyme with demonstrable antitubercular activity $[12,13]$. This contrasts with our results for SerRS and what is predicted for the other Class II aaRS. However, while BirA shares the core six-stranded antiparallel $\beta$-sheet flanked by structurally conserved $\alpha$-helices seen in SerRS and other class II aaRS, the orientation of the loop region involved in nucleoside recogition is significantly different (Supplemental Fig. S2). This difference leads to an alternative conformation of the intermediate whereby the $\mathrm{S}-\mathrm{C} 6^{\prime}-\mathrm{C} 5^{\prime}-\mathrm{C} 4^{\prime}$ torsion angle of biotinoyl-SoHA is $201.8^{\circ}$, resulting in no eclipsing interactions around the $\mathrm{C}^{\prime}-\mathrm{C} 5^{\prime}$ bond (Fig. 6B). Comparatively, the conformation of the biostere linker in biotinoyl-SoHA resembles more that of the intermediate analogues bound to the structurally distinct members of the Class III adenylate-forming enzymes (Fig. 6C). Both share the same 3'-endo conformation of the sugar ring, and a similar $\mathrm{C} 5^{\prime}-\mathrm{C}^{\prime}$ ' bond position relative to the ribose. In the case of the inhibitor conformation bound to the Mycobacterium tuberculosis long-chain-fatty-acid-AMP ligase the sulfone group is positioned in an anti configuration, relative to the $\mathrm{C}^{\prime}$ ' atom, with a $\mathrm{S}$ - $6^{\prime}-\mathrm{C} 5^{\prime}-\mathrm{C} 4^{\prime}$ torsion angle of $179.2^{\circ}$. This pose results in a staggered relation of the $\mathrm{C}^{\prime}$ and $\mathrm{C}^{\prime}{ }^{\prime}$ protons similar to that seen for biotinoyl-SoHA (Fig. 6B and C).

The Class IV NIS members of the adenylate-forming family, are all involved in siderophore biosynthesis [10]. These chelating molecules sequester iron, in nutrient-poor environments and are important virulence factors in pathogenic bacteria [10]. Despite the recognition that this family are suitable targets for antimicrobial development, no structures are available of a representative enzyme bound to the reaction intermediate, or an analogue thereof. Therefore $N$-citryl-ethylenediamine-SoHA was modelled and minimised, by linking the natural substrates observed in the crystal structure of achromobactin synthetase protein D (PDB ID $2 \times 3 \mathrm{~J}$, Fig. 6D). This intermediate seems to be an outlier compared to all other adenylate classes in that the adenine base adopts a syn conformation. The sugar ring has a 2 '-endo conformation, observed in the intermediate of the Class I aaRSs (Fig. 5B and C), but because of the position of the adenine base, the $\mathrm{C} 6^{\prime}-\mathrm{C} 5^{\prime}$ bond is rotated away from the nucleoside scaffold. Despite this difference, the $\mathrm{S}-\mathrm{C}^{\prime}-\mathrm{C} 5^{\prime}-\mathrm{C} 4^{\prime}$ torsion angle is $172.0^{\circ}$, similar to that observed for LeuSoHA, and the angular offset of the 


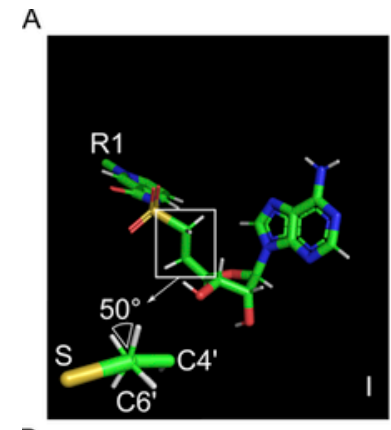

B

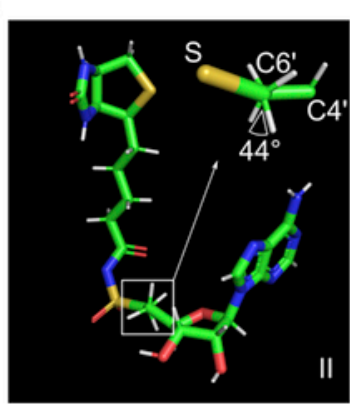

C

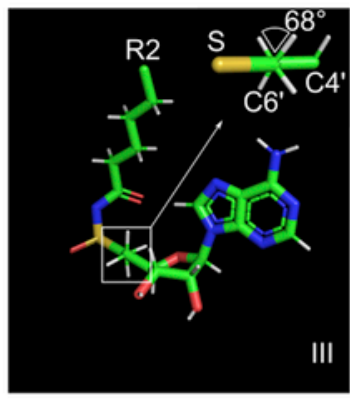

$\mathrm{D}$
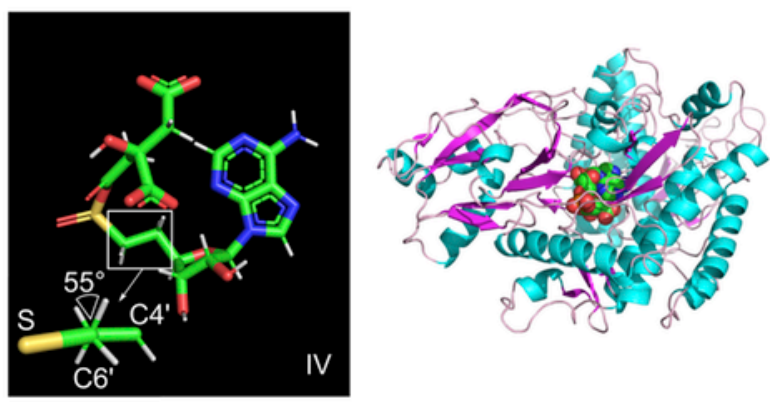

E
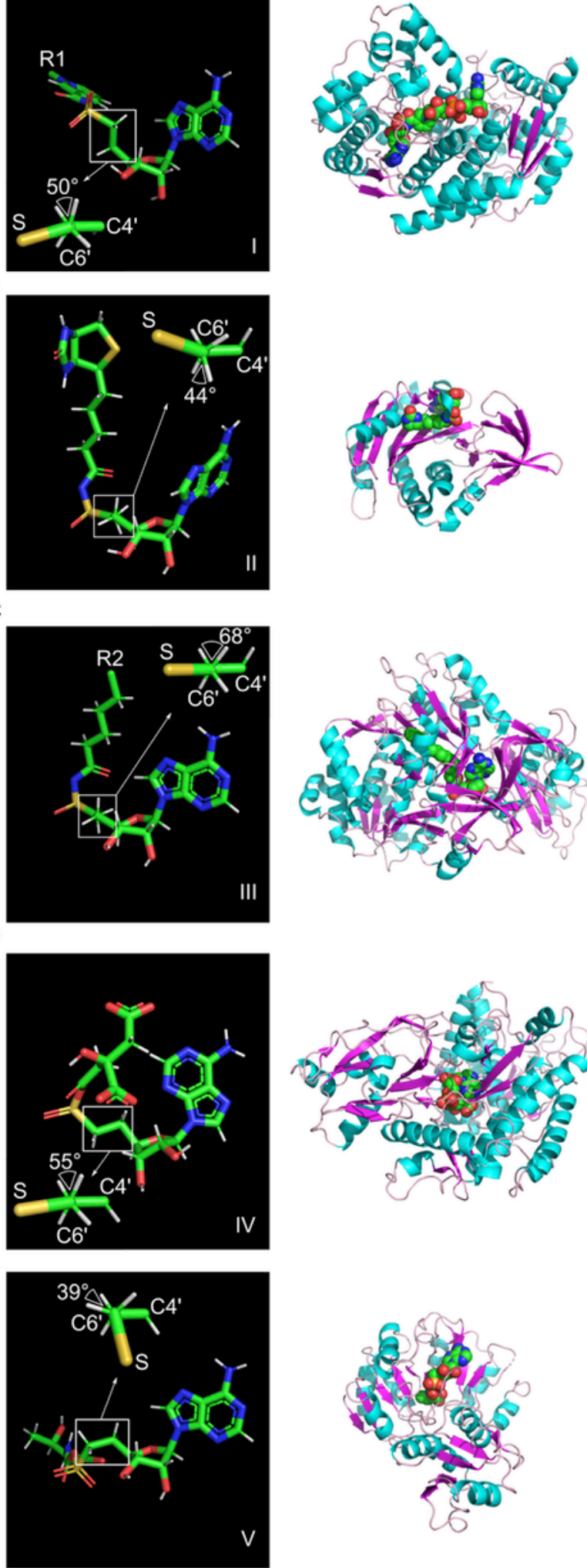

Fig. 6. ( $90 \mathrm{~mm}$ width): Conformation analysis of sulfonamide-linked biosters for the different intermediates of class representative adenylate-forming enzymes. (A) Left: C-5' -(nicotinamide-adenine-dinucleotidyl)-adenosyl-methansulfonamide $\quad\left(\mathrm{R}_{1}=-\right.$-ribose-ADP), Right: Class I crystal structure of Bacillus subtilis $\mathrm{NH}_{3}$-dependent $\mathrm{NAD}+$ syn- thetase (PDB ID 1KQP); (B) Left: C-5'-(biotinoyl)-adenosyl-methansulfonamide, Right: Class II crystal structure of Mycobacterium tuberculosis biotin-protein ligase (PDB ID 3RUX); (C) Left: C-5'-(11-phenoxyundecanoyl)-adenosyl-methansulfonamide $\left(\mathrm{R}_{2}=-\left(\mathrm{CH}_{2}\right)_{5}-\mathrm{O}-\mathrm{Ph}\right)$, Right: Class III crystal structure of Mycobacterium tuberculosis long-chain-fatty-acid-AMP ligase (PDB ID 5HM3); (D) Left: C-5'-(citryl)-adenosyl-methansulfonamide, Right: Class IV crystal structure of Pectobacterium chrysanthemi achromobactin synthetase protein D (PDB ID $2 \times 3 \mathrm{~J})$; (E) Left: C-5'-(threonylcarbamoyl)-adenosyl-methansulfonamide, Right: Class V crystal structure of Sulfolobus tokodaii L-threonylcarbamoyl adenine synthase (PDB ID 4E1B).

$\mathrm{C}^{\prime}$ and $\mathrm{C}^{\prime}$ protons is $55^{\circ}$ reflecting a staggered conformation (Fig. 6D). Finally, the threonylcarbamoyl-adenylate intermediate in the Class V representative $L$-threonylcarbamoyl-adenylate synthase (4E1B, Fig. 6E) has a similar nuceloside binding pose as the Class III inhibitor. Uniquely though, amongst the adenylate-forming superfamily, the sulfone group is positioned at an acute angle to the $\mathrm{C} 4{ }^{\prime}$ atom with a torsion angle of $76.9^{\circ}$. However, the $\mathrm{C}^{\prime}$ and $\mathrm{C}^{\prime}$ protons demonstrate a staggered offset with a torsion angle of $39^{\circ}$ for the closest proton pair (Fig. 6E).

Combined, this family-wide analysis indicates that the $\mathrm{O}^{2}$ ' to $\mathrm{C}$ substitution in the sulfonamide bioisosteres or the acyl-adenylate would likely be tolerated by all classes of the adenylate-forming enzyme superfamily except for the Class II aaRSs.

\section{Discussion and conclusion}

Non-hydrolysable acyl-adenylate analogues of the enzymatic intermediate of a variety of adenylate-forming enzymes have been consistently shown to have inhibitory activity $[2,3]$. Functioning as bi-substrate competitive inhibitors, the potency of these compounds emanates from the entropic favorability of binding over the unlinked substrates. Sulfur-based bioisosteres of the labile phosphoanhydrides have been typically employed, of which the sulfamate containing compounds have proven to be particularly effective [26,27]. In the case of targeting aminoacyl-tRNA synthetases subnanomolar binding has been observed in vitro, but unfortunately this has not translated to in vivo activity due to the high polarity of the compounds. Attempts to modify this scaffold, for prodrug strategies $[28,29]$, has been limited due to the chemical instability of the compound [12]. In this work, we synthesized aminoacylated sulfonamide adenosines IleSoHA $\mathbf{1 4}$ and SerSoHA 15 (Scheme 1), aimed to inhibit their corresponding Class I and II aminoacyl-tRNA synthetase. The rationale for this oxygen-carbon substitution was to make hydrolytically stable aaSA analogues that are resistant to degradation at the $5^{\prime}$-position due to the less electrophilic 5'-carbon atom (Fig. 1A).

Inspired by the work of Shi et al. [12], we first attempted a Boc-Wittig-Horner procedure in order to obtain the $\mathrm{C}-\mathrm{C}$ linked sulfonamide nucleosides. Unfortunately, compound $\mathbf{1 3}$ in our hands decomposed during work-up, in contrast to the previous report. Therefore, we explored two related reaction routes, using compounds $\mathbf{1 6}$ and 18, but both failed to provide the desired products (Scheme 2). A nucleophilic substitution approach was subsequently tried in vain in order to extend the amino acid side chain (Scheme 3). With the intention of solving the degradation problem, we slightly modified the Boc-Wittig-Horner reaction procedure avoiding acidic circumstances. This alteration in the reported reaction procedure enabled us to obtain the desired products 14 and $\mathbf{1 5}$ (Scheme 1) in a reproducible way.

An evaluation of the in vitro inhibitory activity of 14 and 15 surprisingly demonstrated a class correlated difference, with at least a 10000 -fold decrease in the $\mathrm{IC}_{50}$ for the SerSoHA 15 over that reported for the analogous sulfamoyl [20] (Fig. 3). Detailed examination of the modelled SerSoHA bound conformation, employing a $2.1 \AA$ resolution crystal structure of $K$. pneumoniae SerRS soaked with SerSA suggests that an accumulation of torsional penalties, re- 
sulting from the energetically unfavorable eclipsed positions of the $\mathrm{C}^{\prime}$ and $\mathrm{C}^{\prime}{ }^{\prime}$ protons with regard to each other, and with the $\mathrm{C}^{\prime}-$ $\mathrm{S}$ and $\mathrm{C} 4^{\prime}-\mathrm{C}^{\prime}$ bonds respectively, are in part likely to cause the observed loss of activity (Fig. 4C). By itself this appears surprising, as the relative energy between the staggered and eclipsed conformations of butane is only about $4 \mathrm{kcal} / \mathrm{mol}$ [30]. Examination of the other properties of the molecule suggest though that it is the major determinant.

An estimate of the $\mathrm{pKa}$ of the sulfonamide nitrogen predicts it to be deprotonated under physiological conditions in analogy with the sulfamoyl moiety. This same bioisosteric linker has been successfully employed in compounds targeting $M$. tuberculosis biotin ligase, an alternative Class II adenylate-forming enzyme (Fig. 6B and Supplemental Fig. S2). In this particular enzyme, the phosphate makes numerous charge-based interactions with basic residues in the protein active site including a conserved lysine that is essential for activity [21,31]. As the deprotonated sulfonamide effectively replicates these ionic interactions in this birA active site, by extrapolation this should also apply in the case of the aminoacyl-SoHA analogues.

The switch from the $\mathrm{S}-\mathrm{O}(1.577 \AA)$ to a $\mathrm{S}-\mathrm{C}(1.758 \AA)$ bond results in a small shift in bond length $(\Delta=0.181 \AA)$ which may have an effect on the overall conformation of the resultant compound [32]. This value though is within one standard deviation of the observed $\mathrm{S}-\mathrm{C}^{\prime}-\mathrm{C} 5^{\prime}-\mathrm{C} 4$ ' torsion angles from available Class II ligand bound crystal structures suggesting it can be accommodated. Ultimately, improved binding of the two bisubstrate-based competitive inhibitors over the amino acid and ATP substrates, which cumulatively make a similar number of interactions with the aaRS, is dictated by an entropic benefit [33]. It therefore appears that the torsion angle penalty caused by the $\mathrm{O}^{\prime}-\mathrm{C}$ substitution in the bound state of $\mathbf{1 5}$ affects this profoundly.

A comprehensive examination of all Class II aaRSs shows that the conformation modelled for SerSoHA 15 bound to SerRS is not just restricted to this orthologue. Superposition of this scaffold on the intermediate observed in the available structures shows a highly restricted bent conformation, where the $\mathrm{O}^{\prime}-\mathrm{S}$ bond (or $\mathrm{O}^{\prime}-\mathrm{P}$ in the natural adenylate) is found always eclipsing the $\mathrm{C}^{\prime}$ protons (Fig. 5D). This torsion penalty, even for the regular intermediate, appears to be overcome by extensive interactions that are made between the aminoacyl-adenylate and the active sites of the different Class II aaRSs $[34,35]$. In contrast, examination of the intermediate conformation in all available Class I aaRSs shows no eclipsed conformation for the side-groups of the $\mathrm{C} 5^{\prime}-\mathrm{C}^{\prime}$ ' (or $\mathrm{C}^{\prime}-\mathrm{O}$ ), as would be predicted based on the observed inhibitory activity results of IleSoHA 14 (Fig. 3). Together this suggests that the use of the sulfonamide linker in aminoacyl-adenylate intermediate analogues, is suitable for Class I aaRS but should be avoided for Class II enzymes performing the equivalent function.

To evaluate the further use of the sulfonamide-linked bioisosteres as pharmacologically relevant molecules we examined the binding conformation of the acyl-adenylate analogue to additional representatives of all five structurally distinct classes of the adenylate-forming enzyme superfamily (Figs. 2 and 6). In all cases we observed no steric clashes or torsion angle penalties with the introduction of this linker suggesting it could be a viable alternative for this diverse family. Interestingly, as stated above, a sulfonamide based intermediate analogue has been reported to be effective against biotin ligase (BirA), with demonstrable antitubercular activity [12]. Like SerRS, this particular enzyme is a member of the Class II adenylate-forming enzymes which all share a core conserved $\beta$-sheet structure (Figs. 2, 4 and 6). That said, the binding mode in BirA, particular of the nucleoside portion, is significantly different to that seen within the Class II
aaRSs (Supplemental Fig. S2). This ultimately results in a distinct conformation of the intermediate analogue that is more similar to that observed in the functionally diverse Class III family enzymes, where there are no observed issues with torsion angle overlaps.

As a final conclusion, we have observed that a theoretically innocuous atom substitution, from a sulfamate to a sulfonamide, in a known potent class II aaRS inhibitor, has a dramatic negative effect on the inhibitory activity of the resultant compound. Our comprehensive analysis points to a torsion angle penalty as being the likely cause of this loss. This problem is manifested due to conserved conformation of the aminoacyl-adenylate intermediate in all class II aaRS, which is ultimately dictated by the enzymatic spatial arrangement of the $\alpha$-phosphate of ATP and the amino acid carboxylate group during catalysis [34,35]. A comprehensive examination of the acyl-adenylate bound to representative members of all adenylate-forming enzyme classes, shows considerable variation in the conformation of this reaction intermediate between the different groups. Our analysis shows that, with the exception of the class II aaRS, the sulfonamide-based phosphate bioisostere is likely a viable non-hydrolysable linker for developing family-wide bisubstrate inhibitors that work by mimicking the acyl-adenylate. The incorporation of the sulfonamide has been shown to improve chemical stability over other sulfur-based linkers [12], and was more recently shown to limit enzymatic-based disproportionation of the compound [13]. The latter is an important consideration in developing inhibitors that can avoid natural resistance mechanisms [36]. The optimized chemical synthesis strategy outlined here should permit elaboration of such compounds, increasing opportunities to develop much needed antimicrobials.

\section{Experimental section}

\subsection{Reagents and analytical procedures}

Reagents and solvents were purchased from commercial suppliers (Acros, Sigma-Aldrich) and used as provided, unless indicated otherwise. DMF, THF, DCM and $\mathrm{MeOH}$ were of analytical grade and were stored over $4 \AA$ molecular sieves. All other solvents used for reactions were analytical grade and used as provided. Reactions were carried out in oven-dried glassware under a nitrogen atmosphere with stirring at room temperature, unless indicated otherwise. ${ }^{14} \mathrm{C}$-radiolabeled amino acids and scintillation liquid were purchased from PerkinElmer.

${ }^{1} \mathrm{H}$ and ${ }^{13} \mathrm{C}$ NMR spectra of the compounds dissolved in $\mathrm{CDCl}_{3}$, $\mathrm{CD}_{3} \mathrm{OD}$, DMSO- $d_{6}$ or $\mathrm{D}_{2} \mathrm{O}$ were recorded on a Bruker UltraShield Avance $300 \mathrm{MHz}, 400 \mathrm{MHz}$ or when needed on a $600 \mathrm{MHz}$ spectrometer. The chemical shifts are expressed as $\delta$ values in parts per million $(\mathrm{ppm})$, using the residual solvent peaks $\left(\mathrm{CDCl}_{3}:{ }^{1} \mathrm{H}, 7.26 \mathrm{ppm} ;{ }^{13} \mathrm{C}\right.$, 77.16 ppm; DMSO: ${ }^{1} \mathrm{H}, 2.50 \mathrm{ppm} ;{ }^{13} \mathrm{C}, 39.52 \mathrm{ppm} ; \mathrm{D}_{2} \mathrm{O}:{ }^{1} \mathrm{H}, 4.79 \mathrm{ppm}$; $\left.\mathrm{CD}_{3} \mathrm{OD}:{ }^{1} \mathrm{H}, 3.31 \mathrm{ppm} ;{ }^{13} \mathrm{C}, 49.00 \mathrm{ppm}\right)$ as a reference. Coupling constants are reported in Hertz $(\mathrm{Hz})$. The peak patterns are indicated by the following abbreviations: br $\mathrm{s}=$ broad singlet, $\mathrm{d}=$ doublet, $\mathrm{m}=\mathrm{mul}$ tiplet, $\mathrm{q}=$ quadruplet, $\mathrm{s}=$ singlet and $\mathrm{t}=$ triplet. High resolution mass spectra were recorded on an ion-mobility mass spectrometer (SYNAPT G2-Si HDMS, Waters, Milford, US) equipped with a standard ESI interface; samples were infused in 2- propanol/ $\mathrm{H}_{2} \mathrm{O}(1: 1)$ at $3 \mathrm{~mL}$ min-1. For TLC, precoated aluminum sheets were used (Merck, Silica gel 60 F254). The spots were visualized by UV light at $254 \mathrm{~nm}$. Chromatography was performed on ICN silica gel 60A 60-200. Final products (acylated sulfonamide nucleosides) were purified using a semi-prep PLRP-S $100 \AA$ column $(7.5 \times 300 \mathrm{~mm})$ connected to a Merck-Hitachi L6200A Intelligent pump. Eluent compositions are expressed as $\mathrm{v} / \mathrm{v}$. The characterization 
of the final compounds by NMR and mass are provided in the supplementary file. Compounds $\mathbf{2}, \mathbf{3}, \mathbf{8}$ and $\mathbf{9}$ were prepared according to literature procedures (references [37-40], respectively) and proved identical.

\subsection{Chemical synthesis of intermediates and final compounds}

\subsection{1. $N^{6}, N^{6}$-bis-Boc-5'-O-tertbutyldimethylsilyl-2'-3'-}

$O$-isopropylideneadenosine (4)

Compound 3 ( $3.46 \mathrm{~g}, 8.22 \mathrm{mmol}, 1.0$ eq.), 4-dimethylaminopyridine $(0.201 \mathrm{~g}, 1.64 \mathrm{mmol}, 0.2$ eq. $)$ and triethylamine $(2.41 \mathrm{~mL}$, $17.25 \mathrm{mmol}, 2.1$ eq.) were combined and put under an atmosphere of nitrogen, whereafter dissolving the reactants in a 2.4:1 mixture of anhydrous acetonitrile:DMF (48:20 mL, $0.12 \mathrm{M})$. Di- $t$-butyl dicarbonate $(6.28 \mathrm{~g}, 28.8 \mathrm{mmol}, 3.5$ eq. $)$ was dissolved in DMF $(6.0 \mathrm{~mL})$ and added dropwise to the solution. The mixture was stirred for 3 days at room temperature under nitrogen. The solvents were subsequently removed under reduced pressure. The residue was purified by silica gel chromatography (heptane:ethyl acetate 50:50) to give compound $4(4.611 \mathrm{~g}, 90 \%)$ as a light-yellow foam with $\mathrm{R}_{f}=0.68$ (heptane:ethyl acetate 50:50). ${ }^{1} \mathrm{H}$ NMR $\left(300 \mathrm{MHz}, \mathrm{CDCl}_{3}\right): \delta=8.86(\mathrm{~s}, 1 \mathrm{H}), 8.32(\mathrm{~s}$, $1 \mathrm{H}), 6.23$ (d, $J=2.6 \mathrm{~Hz}, 1 \mathrm{H}), 5.19$ (dd, $J=6.1,2.6 \mathrm{~Hz}, 1 \mathrm{H}), 4.93$ (dd, $J=6.1,2.4 \mathrm{~Hz}, 1 \mathrm{H}), 4.43(\mathrm{dd}, J=6.2,3.6 \mathrm{~Hz}, 1 \mathrm{H}), 3.82(\mathrm{ddd}, J=33.3$, $11.3,3.8 \mathrm{~Hz}, 2 \mathrm{H}), 1.63(\mathrm{~s}, 3 \mathrm{H}), 1.41(\mathrm{~s}, 18 \mathrm{H}), 1.39(\mathrm{~s}, 3 \mathrm{H}), 0.83(\mathrm{~s}$, $9 \mathrm{H}), 0.00(\mathrm{~s}, 6 \mathrm{H}) \mathrm{ppm}$.

\subsection{2. $N^{6}, N^{6}$-bis-Boc-2'-3'-O-isopropylideneadenosine (5)}

Compound 4 ( $4.61 \mathrm{~g}, 7.42 \mathrm{mmol}, 1.0$ eq.) was put under an atmosphere of nitrogen and was dissolved in anhydrous tetrahydrofuran (THF, $42.4 \mathrm{~mL}, 0.18 \mathrm{M}$ ). Tetrabutylammonium fluoride trihydrate (4.68 g, $14.83 \mathrm{mmol}, 2.0$ eq.) was dissolved in anhydrous THF $(14.83 \mathrm{~mL})$ and added dropwise to the solution. The mixture was stirred overnight at room temperature under nitrogen. The solvent was removed under reduced pressure. The residue was purified by silica gel chromatography (heptane:ethyl acetate 20:80) to give compound $5(3.61 \mathrm{~g}, 96 \%)$ as a white solid with $\mathrm{R}_{f}=0.61$ (heptane:ethyl acetate 20:80). ${ }^{1} \mathrm{H}$ NMR (300 MHz, DMSO): $\delta=8.88$ (s, 1H), $8.82(\mathrm{~s}, 1 \mathrm{H})$, 6.29 (d, $J=2.6 \mathrm{~Hz}, 1 \mathrm{H}), 5.45$ (dd, $J=6.1,2.6 \mathrm{~Hz}, 1 \mathrm{H}), 5.13(\mathrm{t}, 1 \mathrm{H})$, $5.00(\mathrm{dd}, J=6.2,2.4 \mathrm{~Hz}, 1 \mathrm{H}), 4.29(\mathrm{td}, J=2.5 \mathrm{~Hz}, 1 \mathrm{H}), 3.55-3.50(\mathrm{~m}$, $2 \mathrm{H}), 1.56(\mathrm{~s}, 3 \mathrm{H}), 1.39$ (s, 18H), $1.34(\mathrm{~s}, 3 \mathrm{H}) \mathrm{ppm}$.

\subsection{3. $N^{6}, N^{6}$-bis-Boc-5'-deoxy-2', $3^{\prime}-O$-isopropylidene-5'- oxoadenosine (6)}

Alcohol 5 (0.1 g, $0.197 \mathrm{mmol}, 1.0$ eq. $)$ was dissolved in anhydrous dichloromethane $(7.88 \mathrm{~mL}, 0.025 \mathrm{M})$ and Dess-Martin periodinane $(0.125 \mathrm{~g}, 0.296 \mathrm{mmol}, 1.5 \mathrm{eq}$.) was added in 1 portion. The mixture was put under an atmosphere of nitrogen and stirred for $1.5 \mathrm{~h}$ at room temperature. The reaction solution was cooled to $0^{\circ} \mathrm{C}$ and quenched through adding $1.0 \mathrm{M}$ aqueous sodium thiosulfate $(4.0 \mathrm{~mL})$ and aqueous saturated $\mathrm{NaHCO}_{3}(5.0 \mathrm{~mL})$. The mixture was then stirred for $1.5 \mathrm{~h}$ at room temperature under nitrogen after which the aqueous layer was extracted with dichloromethane $(3 \times)$. The combined organic layers were washed with water and brine and dried over anhydrous $\mathrm{MgSO}_{4}$. Following filtration, the solvent was removed under reduced pressure. The residue was purified by silica gel chromatography (heptane:ethyl acetate 20:80) to give compound $\mathbf{6}$ $(0.088 \mathrm{~g}, 88 \%)$ with $\mathrm{R}_{f}=0.42$ (heptane:ethyl acetate 20:80). ${ }^{1} \mathrm{H}$ NMR (300 MHz, DMSO): $\delta=9.29(\mathrm{~s}, 1 \mathrm{H}), 8.78(\mathrm{~s}, 1 \mathrm{H}), 8.77(\mathrm{~s}, 1 \mathrm{H}), 6.59$ $(\mathrm{s}, 1 \mathrm{H}), 5.55(\mathrm{dd}, J=6.1,1.7 \mathrm{~Hz}, 1 \mathrm{H}), 5.51(\mathrm{~d}, J=6.1 \mathrm{~Hz}, 1 \mathrm{H}), 4.85$ (d, $J=1.7 \mathrm{~Hz}, 1 \mathrm{H}), 1.55(\mathrm{~s}, 3 \mathrm{H}), 1.39(\mathrm{~s}, 18 \mathrm{H}), 1.38(\mathrm{~s}, 3 \mathrm{H}) \mathrm{ppm}$.
4.2.4. 6-Amino- $N^{6}, N^{6}$-bis-Boc-9-[5,6-dideoxy-6-(ethoxysulfonyl)-2,3O-isopropylidene- $\beta$-D-ribo-hex-5-enofuranosyl]-9H-purine (11) and 6-Amino- $N^{6}$-Boc-9-[5,6-dideoxy-6-(ethoxysulfonyl)-2,3-O-

isopropylidene- $\beta$-D-ribo-hex-5-enofuranosyl]-9H-purine (10)

Using alcohol 5 (0.250 g, $0.493 \mathrm{mmol}, 1.0$ eq.), crude aldehyde 6 was obtained as a yellow oil with $\mathrm{R}_{f}=0.42$ (heptane:ethyl acetate 20:80) as decribed above.

Wittig-Horner reactant $9(0.214 \mathrm{~g}, 0.542 \mathrm{mmol}, 1.1 \mathrm{eq}$.$) was put un-$ der nitrogen and dissolved in a 1:1 mixture of anhydrous THF:DMF $(5.0 \mathrm{~mL}, 0.1 \mathrm{M})$. The solution was cooled to $-78^{\circ} \mathrm{C}$ and lithium bis(trimethylsilyl)amide ( $1.08 \mathrm{~mL}, 2.2$ eq., $1.0 \mathrm{M}$ in THF) was added dropwise. The mixture was stirred for $2.5 \mathrm{~h}$ at $-78^{\circ} \mathrm{C}$. Crude aldehyde 6 was dissolved in anhydrous THF $(4.0 \mathrm{~mL})$ and was added to the reaction mixture. The solution was allowed to warm to room temperature and was stirred for 2 days at room temperature. The solvents were removed under reduced pressure and the residue was resuspended into water $(20 \mathrm{~mL})$. The aqueous layer was acidified with aqueous $\mathrm{HCl}(1.0 \mathrm{M})$ to $\mathrm{pH}=4$ and was extracted with ethyl acetate $(3 \times)$. The combined organic layers were washed with water and brine and dried over anhydrous $\mathrm{MgSO}_{4}$. After filtration, the solvent was removed under reduced pressure. The residue was purified by silica gel chromatography (ethyl acetate) to give compounds $\mathbf{1 1}$ $(0.080 \mathrm{~g}, 24 \%)$ with $\mathrm{R}_{f}=0.89$ (ethyl acetate) as a yellow solid and $10(0.086 \mathrm{~g}, 30 \%)$ with $\mathrm{R}_{f}=0.64$ (ethyl acetate) as a yellow oil. ${ }^{1} \mathrm{H}$ NMR $\left(400 \mathrm{MHz}, \mathrm{CDCl}_{3}\right)$ of 11: $\delta=8.84(\mathrm{~s}, 1 \mathrm{H}), 8.11(\mathrm{~s}, 1 \mathrm{H}), 6.82$ (dd, $J=15.2,3.6 \mathrm{~Hz}, 1 \mathrm{H}), 6.39(\mathrm{dd}, J=15.4,1.8 \mathrm{~Hz}, 1 \mathrm{H}), 6.21$ (s, $1 \mathrm{H}), 5.77(\mathrm{~d}, J=5.9 \mathrm{~Hz}, 1 \mathrm{H}), 5.35$ (dd, $J=5.9,2.1 \mathrm{~Hz}, 1 \mathrm{H}), 4.94(\mathrm{~d}$, $J=2.2 \mathrm{~Hz}, 1 \mathrm{H}), 1.62(\mathrm{~s}, 3 \mathrm{H}), 1.51(\mathrm{~s}, 18 \mathrm{H}), 1.50(\mathrm{~s}, 9 \mathrm{H}), 1.44(\mathrm{~s}, 3 \mathrm{H})$ ppm. ${ }^{13} \mathrm{C}$ NMR $\left(101 \mathrm{MHz}, \mathrm{CDCl}_{3}\right)$ of 11: $\delta=152.49,150.96,150.78$, $149.50,144.21,141.76,129.14,128.57,114.58,90.95,85.33,84.56$, $84.40,83.97,83.37,27.86,27.82,26.78,25.18$ ppm. MS (ESI): calcd. for $\mathrm{C}_{29} \mathrm{H}_{41} \mathrm{~N}_{6} \mathrm{O}_{11} \mathrm{~S}_{1}[\mathrm{M}-\mathrm{H}]^{-}$681.3; found 681.2. ${ }^{1} \mathrm{H}$ NMR (400 MHz, $\mathrm{CDCl}_{3}$ ) of 10: $\delta=8.72(\mathrm{~s}, 1 \mathrm{H}), 8.63(\mathrm{~s}, 1 \mathrm{H}), 8.20(\mathrm{~s}, 1 \mathrm{H}), 7.04(\mathrm{dd}$, $J=15.1,4.2 \mathrm{~Hz}, 1 \mathrm{H}), 6.42(\mathrm{~d}, J=13.6 \mathrm{~Hz}, 1 \mathrm{H}), 6.26(\mathrm{~s}, 1 \mathrm{H}), 5.53$ $(\mathrm{d}, J=6.2 \mathrm{~Hz}, 1 \mathrm{H}), 5.25(\mathrm{dd}, J=5.9,3.5 \mathrm{~Hz}, 1 \mathrm{H}), 4.93(\mathrm{~s}, 1 \mathrm{H}), 1.63$ $(\mathrm{s}, 3 \mathrm{H}), 1.56(\mathrm{~s}, 9 \mathrm{H}), 1.43(\mathrm{~s}, 9 \mathrm{H}), 1.41(\mathrm{~s}, 3 \mathrm{H}) \mathrm{ppm} .{ }^{13} \mathrm{C} \mathrm{NMR}$ $\left(101 \mathrm{MHz}, \mathrm{CDCl}_{3}\right)$ of 10: $\delta=153.05,150.32,150.27,149.96,149.92$, $142.61,142.24,128.51,121.90,114.96,90.67,85.27,84.02,83.84$, $83.78,82.18,28.10,27.85,26.95,25.21 \mathrm{ppm}$. MS (ESI): calcd. for $\mathrm{C}_{24} \mathrm{H}_{33} \mathrm{~N}_{6} \mathrm{O}_{9} \mathrm{~S}_{1}[\mathrm{M}-\mathrm{H}]^{-}$581.2; found 581.1.

\subsubsection{C-(2',3'-O-isopropylidene-5'-adenosyl)methansulfonamide (13)}

Palladium on carbon (10 wt \% loading, $0.015 \mathrm{~g}, 0.143 \mathrm{mmol})$ was put under nitrogen. Wittig-Horner compound $10(0.086 \mathrm{~g}, 0.147 \mathrm{mmol}$, 1.0 eq.) was dissolved in anhydrous methanol $(15 \mathrm{~mL}, 0.01 \mathrm{M})$ and added to the catalyst. The atmosphere was exchanged for hydrogen gas and the reaction mixture was vigorously stirred for 3 days at room temperature. After completion of the reaction (ESMS), the mixture was filtered over Celite. The solvent of the filtrate was removed under reduced pressure, affording crude reduced compound $\mathbf{1 2}$ with $\mathrm{R}_{f}=0.10$ (heptane:ethyl acetate 50:50) as a colourless oil. MS (ESI): calcd. for $\mathrm{C}_{24} \mathrm{H}_{35} \mathrm{~N}_{6} \mathrm{O}_{9} \mathrm{~S}_{1}[\mathrm{M}-\mathrm{H}]^{-}$583.2; found 583.2.

Crude compound 12 was put under nitrogen and was dissolved in anhydrous dichloromethane $(5.66 \mathrm{~mL}, 0.026 \mathrm{M})$ and the mixture was cooled to $0^{\circ} \mathrm{C}$. Trifluoroacetic acid (TFA, $0.82 \mathrm{~mL}, 11.03 \mathrm{mmol}$, 75 eq.) was added dropwise after which the mixture was stirred for $2 \mathrm{~h}$ at $0{ }^{\circ} \mathrm{C}$. The mixture was then poured in cooled $\left(0^{\circ} \mathrm{C}\right)$ aqueous saturated $\mathrm{NaHCO}_{3}$, whereafter the aqueous phase was washed with dichloromethane $(3 \times)$. The aqueous layer was subsequently extracted with ethyl acetate $(3 \times)$. The combined organic layers were washed 
with water and brine and dried over anhydrous $\mathrm{MgSO}_{4}$. After filtration, the solvent was removed under reduced pressure. The residue was purified by silica gel chromatography (ethyl acetate:methanol 100:0 $\rightarrow 90: 10)$ to give the TFA salt of compound $13(0.062 \mathrm{~g}, 69 \%)$ with $\mathrm{R}_{f}=0.20$ (ethyl acetate) as a colourless oil. ${ }^{1} \mathrm{H}$ NMR $(400 \mathrm{MHz}$, $\left.\mathrm{CD}_{3} \mathrm{OD}\right): \delta=8.28(\mathrm{~s}, 1 \mathrm{H}), 8.25(\mathrm{~s}, 1 \mathrm{H}), 6.18(\mathrm{~s}, 1 \mathrm{H}), 5.52(\mathrm{~s}, 1 \mathrm{H})$, $5.00(\mathrm{~s}, 1 \mathrm{H}), 4.31(\mathrm{~s}, 1 \mathrm{H}), 3.13(\mathrm{~s}, 2 \mathrm{H}), 2.25(\mathrm{~s}, 2 \mathrm{H}), 1.61(\mathrm{~s}, 3 \mathrm{H})$, $1.40(\mathrm{~s}, 3 \mathrm{H}) \mathrm{ppm} .{ }^{13} \mathrm{C}$ NMR $\left(101 \mathrm{MHz}, \mathrm{CD}_{3} \mathrm{OD}\right): \delta=155.96,152.61$, $148.89,140.48,118.11,115.21,89.74,84.67,83.80,83.78,50.90$, $27.66,26.05,24.18 \mathrm{ppm}$.

\subsection{6. $N$-L-isoleucyl-C-5'-adenosyl-methansulfonamide (14)}

Cesium carbonate $(0.171 \mathrm{~g}, 0.52 \mathrm{mmol}, 6.37$ eq.) was put under nitrogen and cooled to $0{ }^{\circ} \mathrm{C}$. Compound $13(0.050 \mathrm{~g}, 0.082 \mathrm{mmol}$, 1.0 eq.) and $t$-butyloxycarbonyl- $L$-isoleucine hydroxysuccinimide ester $(0.086 \mathrm{~g}, 0.26 \mathrm{mmol}, 3.18$ eq. $)$ were dissolved in anhydrous DMF $(4.37 \mathrm{~mL}, 0.019 \mathrm{M})$ and were added to the base. The mixture was gradually warmed to room temperature and was stirred for 4 days at room temperature. The solvent was then removed under reduced pressure and the residue was resuspended in dichloromethane:methanol 90:10. The suspension was filtered over Celite, whereafter the solvents were removed under reduced pressure, giving the crude isoleucine coupled compound with $\mathrm{R}_{f}=0.64$ (dichloromethane:methanol 90:10) as a yellow solid.

The crude isoleucine coupled compound was put under nitrogen and was cooled to $0^{\circ} \mathrm{C}$. An $8: 2(\mathrm{v} / \mathrm{v})$ mixture of trifluoroacetic acid:water ( $0.21 \mathrm{~mL}, 2.81 \mathrm{mmol}, 34$ eq.:0.05 mL, $2.90 \mathrm{mmol}, 35$ eq.) was added dropwise. The mixture was stirred for $3 \mathrm{~h}$ at room temperature after which water was added and the mixture was lyophilized, affording a yellow oil.

The crude product was purified by preparative reversed-phase high-performance liquid chromatography with a PLRP-S $100 \AA$ column connected to a Merck-Hitachi L6200A intelligent pump at a flow rate of $8.0 \mathrm{~mL} / \mathrm{min}$ for $40 \mathrm{~min}$. Hereto, following eluent was used: Milli-Q purified water: 5 min acetonitrile:water 5:95 (v/v); followed by a linear gradient of acetonitrile in $30 \mathrm{~min}$ from $5 \%$ to $95 \%$ and re-equilibrating in $5 \mathrm{~min}$ from $95 \%$ to $5 \%$. The retention time of the product was $18.0 \mathrm{~min}$. The appropriate fractions were pooled and lyophilized to afford the final compound 14 (IleSoHA, $0.003 \mathrm{~g}$, $5 \%)$ as a white powder. ${ }^{1} \mathrm{H}$ NMR $\left(600 \mathrm{MHz}, \mathrm{D}_{2} \mathrm{O}\right): \delta=8.35(\mathrm{~s}, 1 \mathrm{H})$, $8.32(\mathrm{~s}, 1 \mathrm{H}), 6.00(\mathrm{~d}, J=5.1 \mathrm{~Hz}, 1 \mathrm{H}), 4.78(\mathrm{t}, J=5.2 \mathrm{~Hz}, 1 \mathrm{H}), 4.26$ $(\mathrm{t}, J=4.9 \mathrm{~Hz}, 1 \mathrm{H}), 4.16(\mathrm{dd}, J=11.2,6.4 \mathrm{~Hz}, 1 \mathrm{H}), 3.61(\mathrm{~d}, J=4.2 \mathrm{~Hz}$, $1 \mathrm{H}), 3.31-3.25$ (m, 2H), 2.14 (dd, $J=15.8,6.9 \mathrm{~Hz}, 2 \mathrm{H}), 1.94-1.87$ (m, $1 \mathrm{H}), 1.39-1.31(\mathrm{~m}, 1 \mathrm{H}), 1.15-1.08(\mathrm{~m}, 1 \mathrm{H}), 0.89(\mathrm{~d}, J=7.0 \mathrm{~Hz}, 3 \mathrm{H})$, $0.80(\mathrm{t}, J=7.4 \mathrm{~Hz}, 3 \mathrm{H}) \mathrm{ppm} .{ }^{13} \mathrm{C}$ NMR $\left(151 \mathrm{MHz}, \mathrm{D}_{2} \mathrm{O}\right): \delta=174.57$, $150.68,148.32,145.52,142.66,119.03,88.55,82.81,73.45,72.87$, $59.85,48.19,36.29,26.92,23.96,14.43,10.86$ ppm. MS (ESI): calcd. for $\mathrm{C}_{17} \mathrm{H}_{28} \mathrm{~N}_{7} \mathrm{O}_{6} \mathrm{~S}_{1}[\mathrm{M}+\mathrm{H}]^{+} 458.2$; found 458.1 .

\subsection{7. $N$-L-seryl-C-5'-adenosyl-methansulfonamide (15)}

Cesium carbonate $(0.116 \mathrm{~g}, 0.36 \mathrm{mmol}, 4.0$ eq.) was put under an atmosphere of nitrogen and was cooled to $0^{\circ} \mathrm{C}$. Compound $\mathbf{1 3}$ $(0.043 \mathrm{~g}, \quad 0.089 \mathrm{mmol}, 1.0$ eq. $)$ and $t$-butyloxycarbonyl- $O$-benzyl- $L$-serine hydroxysuccinimide ester $(0.070 \mathrm{~g}, 0.18 \mathrm{mmol}, 2.0$ eq. $)$ were dissolved in anhydrous DMF $(2.93 \mathrm{~mL}, 0.03 \mathrm{M})$ and were added to the base. The mixture was gradually warmed to room temperature and was stirred for 2 days at room temperature. The solvent was then removed under reduced pressure and the residue was resuspended in dichloromethane:methanol 90:10. The suspension was filtered over Celite, whereafter the solvents were removed under reduced pressure. The residue was purified by silica gel chromatography (ethyl acetate:methanol 95:5 $\rightarrow$ 90:10) to give serine coupled compound
(0.021 g, 31\%) with $\mathrm{R}_{f}=0.43$ (ethyl acetate:methanol 90:10) as a white solid. HRMS (ESI): calcd. for $\mathrm{C}_{34} \mathrm{H}_{47} \mathrm{~N}_{7} \mathrm{O}_{11} \mathrm{~S}_{1} \mathrm{Na}_{1}[\mathrm{M}+\mathrm{Na}]^{+}$ 784.29465; found 784.3362.

Palladium on carbon (10 wt \% loading, $0.003 \mathrm{~g}, 0.028 \mathrm{mmol})$ was placed under a nitrogen blanket, while the serine coupled compound $(0.021 \mathrm{~g}, 0.028 \mathrm{mmol}, 1.0$ eq.) was dissolved in anhydrous methanol $(2.69 \mathrm{~mL}, 0.01 \mathrm{M})$ and added to the catalyst. The atmosphere was exchanged for hydrogen gas and the reaction mixture was vigorously stirred for 2 days at room temperature. The mixture was then filtered over Celite. The filtrate was evaporated under reduced pressure, giving the crude debenzylated compound.

The crude debenzylated compound was put under nitrogen and a $8: 2(\mathrm{v} / \mathrm{v})$ mixture of trifluoroacetic acid:water $(0.04 \mathrm{~mL}, 0.59 \mathrm{mmol}$, 21 eq.:0.01 mL, $0.61 \mathrm{mmol}, 22$ eq.) was added. The mixture was then stirred for $3 \mathrm{~h}$ at room temperature. Excess water was then added and the reaction mixture was lyophilized, giving a transparent oil.

The crude product was purified by preparative RP-HPLC as described for 14. The retention time of the product was $17.6 \mathrm{~min}$. The appropriate fractions were pooled and lyophilized to afford the desired compound 15 (SerSoHA, $0.002 \mathrm{~g}, 17 \%$ ) as a white powder. ${ }^{1} \mathrm{H}$ NMR $\left(600 \mathrm{MHz}, \mathrm{D}_{2} \mathrm{O}\right): \delta=8.30(\mathrm{~s}, 1 \mathrm{H}), 8.16(\mathrm{~s}, 1 \mathrm{H}), 8.10(\mathrm{~s}, 1 \mathrm{H}), 5.91$ $(\mathrm{d}, J=5.3 \mathrm{~Hz}, 1 \mathrm{H}), 4.16(\mathrm{t}, J=4.9 \mathrm{~Hz}, 1 \mathrm{H}), 4.10(\mathrm{dt}, J=9.0,4.6 \mathrm{~Hz}$, $1 \mathrm{H}), 3.84-3.77$ (m, 2H), 3.68 (t, $J=4.5 \mathrm{~Hz}, 1 \mathrm{H}), 3.23$ (pd, $J=14.0$, $5.6 \mathrm{~Hz}, 2 \mathrm{H}), 2.14-1.98(\mathrm{~m}, 2 \mathrm{H}) \mathrm{ppm} .{ }^{13} \mathrm{C} \mathrm{NMR}\left(151 \mathrm{MHz}, \mathrm{D}_{2} \mathrm{O}\right)$ : $\delta=170.86,160.16,155.46,152.69,148.72,139.81,118.72,87.31$, 82.36, 73.17, 72.74, 60.68, 56.88, 47.81, 27.08 ppm. HRMS (ESI): calcd. for $\mathrm{C}_{14} \mathrm{H}_{20} \mathrm{~N}_{7} \mathrm{O}_{7} \mathrm{~S}_{1}[\mathrm{M}-\mathrm{H}]^{-} 430.1150$; found 430.1144 .

\subsection{Cloning, expression and purification of E. coli SerRS and IleRS and $K$. pneumoniae SerRS}

The E. coli SerRS and IleRS were recombinantly expressed and purified using the previously described procedures [20]. In the case of the Klebsiella pneumoniae SerRS the encoding sequence was amplified by PCR from a genomic DNA preparation from the strain $K$. pneumoniae BAA 1705. The reaction was performed using Phusion polymerase (New England Biolabs) and the primers 5'-gcgaacagattggtggtATGCTCGATCCCAATCTGCTG-3' and 5'-ttgttagcagaagettaTTAGCCGATATATTCGAGGCCG-3', where the capitalized letters correspond to the annealing sequence. The purified PCR product was cloned into the linearized pETRUK plasmid, an in-house derivative of the SUMO fusion vector pETHSUL [41] containing a modified sequence for a $\mathrm{pI}$ enhanced SUMO tag. The integrity of the pETRUK-KpSerRS construct was confirmed by sequencing. This construct was transformed into Rosetta 2 (DE3) pLysS strain (EMD biosciences). A single clone was grown in $2 \mathrm{~L}$ of ZYP-5052 auto-induction medium [42] supplemented with chloramphenicol $(10 \mu \mathrm{g} / \mathrm{mL})$, ampicillin $(100 \mu \mathrm{g} / \mathrm{mL})$ and $1 \mathrm{ml}$ of antifoam SE-15 (Sigma Aldrich). The culture was grown at $24^{\circ} \mathrm{C}$ overnight until it reached an $\mathrm{OD}_{600 \mathrm{~nm}}$ of 4. At this point, the temperature was decreased to $18^{\circ} \mathrm{C}$. After a further $24 \mathrm{~h}$ incubation, cells were harvested by centrifugation at $6000 \mathrm{~g}$ at $4{ }^{\circ} \mathrm{C}$. The cell pellet was resuspended in approximately 4 times w/v of cation exchange buffer A (CEXA; $25 \mathrm{mM}$ Hepes $\mathrm{pH} 8$, $200 \mathrm{mM} \mathrm{NaCl}, 5 \mathrm{mM} \beta$-mercaptoethanol) and then stored at $-20^{\circ} \mathrm{C}$. The frozen cell resuspension was quickly thawed and diluted a further two-fold in CEXA buffer. $100 \mathrm{U}$ cryonase (Takara) and $10 \mathrm{mM}$ (final concentration) $\mathrm{MgCl}_{2}$ were added to the slurry and the cells were lysed by sonication on ice. The resulting lysate was clarified by centrifugation at $18,000 \mathrm{~g}$ at $4{ }^{\circ} \mathrm{C}$ for $30 \mathrm{~min}$ and the supernatant was loaded onto a HiTrap SP HP column (GE Healthcare Life Sciences). The tagged KpSerRS was eluted from the column using a linear gradient of cation exchange buffer B (CEXB; 25 mM Hepes $\mathrm{pH} 8$, 
$1000 \mathrm{mM} \mathrm{NaCl}, 5 \mathrm{mM} \beta$-ME). Protein fractions were combined and the SUMO tag removed by addition of recombinant SUMO hydrolase in a 1:250 (hydrolase: fusion protein) mass ratio. The cleavage reaction was immediately placed in Spectra/Por dialysis tubing (standard regenerated cellulose tubing with size $12-14 \mathrm{kDa}$ ) and the sample was dialyzed against $1 \mathrm{~L}$ of anion exchange buffer A (AEXA; $20 \mathrm{mM}$

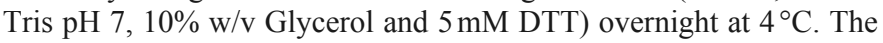
dialysis bag was placed in a fresh $1 \mathrm{~L}$ of AEXA buffer for an additional $2 \mathrm{~h}$ at $4{ }^{\circ} \mathrm{C}$ to remove the remaining salt, then the retentate was applied to the same HiTrap SP HP column to subtract SUMO tag and initial contaminating proteins. Further purification was carried out by anion exchange chromatography using a HiTrap Q HP column (GE Healthcare Life Sciences). Fractions corresponding to the KpSerRS were pooled and the protein precipitated by addition of $2.8 \mathrm{M}$ ammonium sulfate and $1 \mathrm{mM}$ EDTA. This sample was stored at $4{ }^{\circ} \mathrm{C}$ until required.

\subsection{Total tRNA purification and aminoacylation assay}

The total tRNA pool was extracted and purified from BL21 (DE3) using the previously described procedure with a minor modification [20]. Following resuspension of the final isopropanol precipitated tRNA in assay buffer $\left(20 \mathrm{mM}\right.$ Tris $\mathrm{pH} 7.5,10 \mathrm{mM} \mathrm{MgCl}_{2}, 100 \mathrm{mM}$ $\mathrm{KCl}, 2.5 \mathrm{mM} \beta$-ME) the sample was incubated at $85^{\circ} \mathrm{C}$ for $5 \mathrm{~min}$ and then allowed to cool down to room temperature on the bench before performing the aminoacylation assay.

The inhibitory activity of SerSoHA 15 and IleSoHA 14 (and the SA analogues) were assessed using the previously described radiolabel transfer assay [20]. Briefly, purified $10 \mathrm{nME}$. coli IleRS or $2 \mathrm{nM} E$. coli SerRS in assay buffer as mentioned before was pre-incubated with the corresponding compound, at different concentrations, at $37{ }^{\circ} \mathrm{C}$ in the presence of $50 \mu \mathrm{M}$ of the appropriate ${ }^{14} \mathrm{C}$-labeled amino acid, $2 \mathrm{mg}$ / $\mathrm{mL}$ tRNA and $0.5 \mathrm{mg} / \mathrm{mL}$ inorganic pyrophosphatase. After $10 \mathrm{~min}$, the reaction was initiated by adding pre-warmed ATP at a final concentration of $500 \mu \mathrm{M}$. Upon reaching $6 \mathrm{~min}, 4 \mu \mathrm{L}$ quenching buffer $(0.2 \mathrm{M}$ sodium acetate $\mathrm{pH} 4,0.1 \% \mathrm{~N}$-lauroylsarcosine and $5 \mathrm{mM}$ unlabeled amino acid) was added to the mixture. $20 \mu \mathrm{L}$ was spotted on $3 \mathrm{MM}$ Whatmann paper, precipitated using cold $10 \%$ TCA, washed twice with $10 \%$ TCA and once with acetone and dried. Addition of $12 \mathrm{~mL}$ scintillation liquid was followed by measurement of the radioactivity using scintillation counter.

\subsection{Crystallization and structure determination}

Prior to crystallization, the ammonium sulphate precipitated KpSerRS was pelleted and resuspended in size exclusion chromatography (SEC) buffer ( $10 \mathrm{mM}$ Tris $\mathrm{pH} 7,100 \mathrm{mM} \mathrm{NaCl}, 5 \mathrm{mM}$ DTT). The sample was loaded onto a Superdex 200 10/300 GL column (GE Healthcare Life Sciences) equilibrated in the same buffer. Fractions containing the eluted protein were concentrated using a microspin centrifugal filter device with PES $10 \mathrm{KDa}$ (VWR international) to $10 \mathrm{mg} / \mathrm{ml}$. Initial crystallization screens was performed using mosquito liquid transfer robot and sitting drop vapor diffusion method. Single crystals were produced by hanging drop vapor diffusion mixing $1 \mu \mathrm{L} \mathrm{KpSerRS}(10 \mathrm{mg} / \mathrm{mL})$ with $1 \mu \mathrm{L}$ reservoir solution $(100 \mathrm{mM}$ MES/imidazole buffer system $1 \mathrm{pH} 6.5,50 \mathrm{mM} \mathrm{CaCl}_{2}, 7.5 \%$ w/v PEG 8000 and $20 \% \mathrm{v} / \mathrm{v}$ ethylene glycol) at $20^{\circ} \mathrm{C}$. These crystals were soaked with $1 \mathrm{mM} 5^{\prime}-O$-( $N$-( $L$-seryl $)$-sulfamoyl)adenosine [20] for $1 \mathrm{~h}$ in similar solution contain $10 \% \mathrm{w} / \mathrm{v}$ PEG 8000 . The soaked crystals were transferred to cryoloops and flash frozen in liquid nitrogen. Diffraction data was collected to on ESRF beamline MASSIF-3 (Grenoble, France). The data were processed using auto-
PROC [43]. The initial structure, containing a single protomer in the asymmetric unit, was solved by molecular replacement with Phaser using Aquifex aeolicus SerRS structure 2DQ3 as a model [44]. Further iterative improvement of the model was performed by manual building in coot followed by refinement using Buster 2.10.3 [45].

\subsection{Computational analysis}

As the bound LeuSA in the available structure of Thermus thermophilus LeuRS (PDB ID 2V0C) is split into two chemical moieties (the amino acid and 5'-sulfamoyl modified nucleoside) the structure was re-refined with a new geometrical restraints file encapsulating the full chemical entity. A suitable crystallographic information file for LeuSA, corresponding to the ligand ID LSS in the PDB, was generated using the grade webserver (http://grade.globalphasing.org). Using the deposited model and structure factor data, the full LeuSA was placed into the calculated electron density map. This model was then refined using Buster [45] applying a single TLS group to the whole protein chain. The resulting $R$ and $R_{\text {free }}$ values of 0.1730 and 0.1927 , respectively, were $0.7 \%$ better than those reported for the original model [46].

Modelling of the $\mathrm{O}-\mathrm{C}$ of substitution of the various acyl-adenylate analogues was carried out using the Schrodinger Maestro software. The software was first used place or replace H-atoms in the structures of $K$. pneumoniae SerRS, the re-refined $T$. thermophilus LeuRS-LeuSA complex, Bacillus subtilis $\mathrm{NH}_{3}$-dependent NAD + synthetase (PDB ID 1KQP [47]; Mycobacterium tuberculosis biotin-protein ligase (PDB ID 3RUX, [21]), M. tuberculosis long-chain-fatty-acid-AMP ligase (PDB ID 5HM3 [48]); Pectobacterium chrysanthemi achromobactin synthetase protein D (PDB ID $2 \times 3$ J [49]) and the Sulfolobus tokodaii L-threonylcarbamoyl adenine synthase (PDB ID 4E1B, [11]). The H-bonding was then optimized before performing a restrained minimization of the protein and ligand employing the OPLS3e force field [50]. The resultant structure was then used to perform the appropriate atom substitutions. In the case of the $P$. chrysanthemi achromobactin synthetase protein $\mathrm{D}$, the original structure contained ATP and (3' S) - N-citryl-ethylenediamine [49], therefore the ethylenediamine atoms were removed and the citrate molecule linked to the $\alpha$-phosphate, keeping the resultant pyrophosphate. This structure then went under a second round or restrained energy minimization prior to atom substitution.

\section{Funding}

This work was supported by the Research Fund Flanders [Fonds Wetenschappelijk Onderzoek, $1109117 \mathrm{~N}$ to D.D.R., G077814N to S.S. and A.V., G0A4616N to S.W. and A.V., 1 S53516N to S. D. G.]; and the KU Leuven Research Fund [3M14022 to S.W. and A.V.]; and the Chinese Scholarship Council [to L.P.].

\section{Conflicts of interest}

No conflicts of interest are declared.

\section{Acknowledgement}

The authors thank the Belgian FWO for providing a $\mathrm{PhD}$ Fellowship of the Research Foundation - Flanders to Dries De Ruysscher and a SB Fellowship to Steff De Graef, the China Scholarship Council for providing a scholarship to Luping Pang and KU Leuven for financial support. Mass spectrometry was made possible by the support of the Hercules Foundation of the Flemish Government 
[20100225E7]. We are also indebted to Luc Baudemprez for help with NMR spectra measurement.

\section{Appendix A. Supplementary data}

Supplementary data to this article can be found online.

\section{References}

[1] S. Schmelz, J.H. Naismith, Adenylate-forming enzymes, Curr. Opin. Struct. Biol. 19 (2009) 666-671.

[2] B.P. Duckworth, K.M. Nelson, C.C. Aldrich, Adenylating enzymes in Mycobacterium tuberculosis as drug targets, Curr. Top. Med. Chem. 12 (2012) 766-796.

[3] G.H.M. Vondenhoff, A. Van Aerschot, Aminoacyl-tRNA synthetase inhibitors as potential antibiotics, Eur. J. Med. Chem. 46 (2011) 5227-5236.

[4] J.J. Perona, A. Hadd, Structural diversity and protein engineering of the aminoacyl-tRNA synthetases, Biochemistry 51 (2012) 8705-8729.

[5] G. Eriani, M. Delarue, O. Poch, J. Gangloff, D. Moras, Partition of transfer-RNA synthetases into 2 classes based on mutually exclusive sets of sequence motifs, Nature 347 (1990) 203-206.

[6] L. Aravind, V. Anantharaman, E.V. Koonin, Monophyly of class I aminoacyl tRNA synthetase, USPA, ETFP, photolyase, and PP-ATPase nucleotide-binding domains: implications for protein evolution in the RNA world, Proteins Struct. Funct. Genet. 48 (2002) 1-14.

[7] B.H. Dessailly, O.C. Redfern, A.L. Cuff, C.A. Orengo, Detailed analysis of function divergence in a large and diverse domain superfamily: toward a refined protocol of function classification, Structure 18 (2010) 1522-1535.

[8] P.A. Reche, Lipoylating and biotinylating enzymes contain a homologous catalytic module, Protein Sci. 9 (2000) 1922-1929.

[9] A.M. Gulick, Conformational dynamics in the acyl-CoA synthetases, adenylation domains of non-ribosomal peptide synthetases, and firefly luciferase, ACS Chem. Biol. 4 (2009) 811-827.

[10] C.S. Carroll, M.M. Moore, Ironing out siderophore biosynthesis: a review of non-ribosomal peptide synthetase (NRPS)-independent siderophore synthetases, Crit. Rev. Biochem. Mol. Biol. 53 (2018) 356-381.

[11] C. Parthier, S. Gorlich, F. Jaenecke, C. Breithaupt, U. Brauer, U. Fandrich, D. Clausnitzer, U.F. Wehmeier, C. Bottcher, D. Scheel, M.T. Stubbs, The O-carbamoyltransferase TobZ catalyzes an ancient enzymatic reaction, Angew. Chem. Int. Ed. 51 (2012) 4046-4052.

[12] C. Shi, D. Tiwari, D.J. Wilson, C.L. Seiler, D. Schnappinger, C.C. Aldrich, Bisubstrate inhibitors of biotin protein ligase in Mycobacterium tuberculosis resistant to cyclonucleoside formation, ACS Med. Chem. Lett. 4 (2013) 1213-1217.

[13] M.R. Bockman, C.A. Engelhart, S. Dawadi, P. Larson, D. Tiwari, D.M. Ferguson, D. Schnappinger, C.C. Aldrich, Avoiding antibiotic inactivation in $\mathrm{My}-$ cobacterium tuberculosis by Rv3406 through strategic nucleoside modification, ACS Infect. Dis. 4 (2018) 1102-1113.

[14] C.H. Qiao, A. Gupte, H.I. Boshoff, D.J. Wilson, E.M. Bennett, R.V. Somu, C.E. Barry, C.C. Aldrich, 5 '-O- (N-Acyl)sulfamoyl adenosines as antitubercular agents that inhibit MbtA: an adenylation enzyme required for siderophore biosynthesis of the mycobactins, J. Med. Chem. 50 (2007) 6080-6094.

[15] J.G. Hurdle, A.J. O'Neill, I. Chopra, Prospects for aminoacyl-tRNA synthetase inhibitors as new antimicrobial agents, Antimicrob. Agents Chemother. 49 (2005) 4821-4833.

[16] J.S. Tao, P. Schimmel, Inhibitors of aminoacyl-tRNA synthetases as novel anti-infectives, Expert Opin. Investig. Drugs 9 (2000) 1767-1775.

[17] J. Lee, S.U. Kang, S.Y. Kim, S.E. Kim, M.K. Kang, Y.J. Jo, S. Kim, Ester and hydroxamate analogues of methionyl and isoleucyl adenylates as inhibitors of methionyl-tRNA and isoleucyl-tRNA synthetases, Bioorg. Med. Chem. Lett 11 (2001) 961-964.

[18] J. Lee, S.E. Kim, J.Y. Lee, S.Y. Kim, S.U. Kang, S.H. Seo, M.W. Chun, T. Kang, S.Y. Choi, H.O. Kim, N-alkoxysulfamide, N-hydroxysulfamide, and sulfamate analogues of methionyl and isoleucyl adenylates as inhibitors of methionyl-tRNA and isoleucyl-tRNA synthetases, Bioorg. Med. Chem. Lett 13 (2003) 1087-1092.

[19] B. Gadakh, S. Smaers, J. Rozenski, M. Froeyen, A. Van Aerschot, 5 '-(N-aminoacyl)-sulfonamido-5 '-deoxyadenosine: attempts for a stable alternative for aminoacyl-sulfamoyl adenosines as aaRS inhibitors, Eur. J. Med. Chem. 93 (2015) 227-236

[20] B. Zhang, S. De Graef, M. Nautiyal, L.P. Pang, B. Gadakh, M. Froeyen, L. Van Mellaert, S.V. Strelkov, S.D. Weeks, A. Van Aerschot, Family-wide analysis of aminoacyl-sulfamoyl-3-deazaadenosine analogues as inhibitors of aminoacyl-tRNA synthetases, Eur. J. Med. Chem. 148 (2018) 384-396.
[21] B.P. Duckworth, T.W. Geders, D. Tiwari, H.I. Boshoff, P.A. Sibbald, C.E. Barry, D. Schnappinger, B.C. Finzel, C.C. Aldrich, Bisubstrate adenylation inhibitors of biotin protein ligase from Mycobacterium tuberculosis, Chem. Biol. 18 (2011) 1432-1441.

[22] S. Cusack, C. Berthetcolominas, M. Hartlein, N. Nassar, R. Leberman, A second class of synthetase structure revealed by X-ray-analysis of escherichia coli seryl-tRNA-synthetase at $2.5 \AA$, Nature 347 (1990) 249-255.

[23] M. Fujinaga, C. Berthetcolominas, A.D. Yaremchuk, M.A. Tukalo, S. Cusack, Refined crystal structure of seryl-tRNA synthetase from thermus thermophilus at 2.5 A resolution, J. Mol. Biol. 234 (1993) 222-233.

[24] J.C. Shelley, A. Cholleti, L.L. Frye, J.R. Greenwood, M.R. Timlin, M. Uchimaya, Epik: a software program for pK (a) prediction and protonation state generation for drug-like molecules, J. Comput. Aided Mol. Des. 21 (2007) 681-691.

[25] R.V. Somu, H. Boshoff, C.H. Qiao, E.M. Bennett, C.E. Barry, C.C. Aldrich, Rationally designed nucleoside antibiotics that inhibit siderophore biosynthesis of Mycobacterium tuberculosis, J. Med. Chem. 49 (2006) 31-34.

[26] A.K. Forrest, R.L. Jarvest, L.M. Mensah, P.J. O'Hanlon, A.J. Pope, R.J. Sheppard, Aminoalkyl adenylate and aminoacyl sulfamate intermediate analogues differing greatly in affinity for their cognate Staphylococcus aureus aminoacyl tRNA synthetases, Bioorg. Med. Chem. Lett 10 (2000) 1871-1874.

[27] M.J.B. Brown, L.M. Mensah, M.L. Doyle, N.J.P. Broom, N. Osbourne, A.K. Forrest, C.M. Richardson, P.J. O'Hanlon, A.J. Pope, Rational design of femtomolar inhibitors of isoleucyl tRNA synthetase from a binding model for pseudomonic acid-A, Biochemistry 39 (2000) 6003-6011.

[28] P. Van de Vijver, G.H.M. Vondenhoff, T.S. Kazakov, E. Semenova, K Kuznedelov, A. Metlitskaya, A. Van Aerschot, K. Severinov, Synthetic microcin $\mathrm{C}$ analogs targeting different aminoacyl-tRNA synthetases, J. Bacteriol. 191 (2009) 6273-6280.

[29] G.H.M. Vondenhoff, B. Blanchaert, S. Geboers, T. Kazakov, K.A. Datsenko, B.L. Wanner, J. Rozenski, K. Severinov, A. Van Aerschot, Characterization of peptide chain length and constituency requirements for YejABEF-mediated uptake of microcin C analogues, J. Bacteriol. 193 (2011) 3618-3623.

[30] P.Y. Bruice, Organic Chemistry, sixth ed., Pearson, Santa Barbara, 2011.

[31] Q.J. Ma, Y. Akhter, M. Wilmanns, M.T. Ehebauer, Active site conformational changes upon reaction intermediate biotinyl-5'-AMP binding in biotin protein ligase from Mycobacterium tuberculosis, Protein Sci. 23 (2014) 932-939.

[32] F.H. Allen, O. Kennard, D.G. Watson, L. Brammer, A.G. Orpen, R. Taylor, Tables of bond lenghts determined by X-ray and neutron-diffraction. 1. Bond lenghts in organic-compounds, J. Chem. Soc., Perkin Trans. 2 (1987) S1-S19.

[33] W.P. Jencks, On the attribution and additivity of binding energies, Proc. Natl. Acad. Sci. U.S.A. 78 (1981) 4046-4050.

[34] E.A. First, Catalysis of the tRNA aminoacylation reaction, in: M. Ibba, C. Francklyn, S. Cusack (Eds.), The Aminoacyl-tRNA Synthetases, Landes Bioscience, Georgetown, 2005, pp. 328-352.

[35] J.J. Perona, I. Gruic-Sovulj, Synthetic and editing mechanisms of aminoacyl-tRNA synthetases, Aminoacyl-Trna Synthetases in Biol. Med. 344 (2014) $1-41$.

[36] V. Agarwal, G. Vondenhoff, B. Gadakh, K. Severinov, A. Van Aerschot, S.K. Nair, Exploring the substrate promiscuity of an antibiotic inactivating enzyme, Med. Chem. Commun. 5 (2014) 1567-1570.

[37] K. Devkota, B. Lohse, Q. Liu, M.W. Wang, D. Staerk, J. Berthelsen, R.P. Clausen, Analogues of the natural product sinefungin as inhibitors of EHMT1 and EHMT2, ACS Med. Chem. Lett. 5 (2014) 293-297.

[38] C. Sheu, P. Kang, S. Khan, C.S. Foote, Low-temperature photosensitized oxidation of a guanosine derivative and formation of an imidazole ring-opened product, J. Am. Chem. Soc. 124 (2002) 3905-3913.

[39] J. Vannada, E.M. Bennett, D.J. Wilson, H.I. Boshoff, C.E. Barry, C.C. Aldrich, Design, synthesis, and biological evaluation of beta-ketosulfonamide adenylation inhibitors as potential antitubercular agents, Org. Lett. 8 (2006) 4707-4710.

[40] D.C. Reuter, J.E. McIntosh, A.C. Guinn, A.M. Madera, Synthesis of Vinyl Sulfonamides Using the Horner Reaction, Synthesis-Stuttgart, 20032321-2324.

[41] S.D. Weeks, M. Drinker, P.J. Loll, Ligation independent cloning vectors for expression of SUMO fusions, Protein Expr. Purif. 53 (2007) 40-50.

[42] F.W. Studier, Protein production by auto-induction in high-density shaking cultures, Protein Expr. Purif. 41 (2005) 207-234.

[43] C. Vonrhein, C. Flensburg, P. Keller, A. Sharff, O. Smart, W. Paciorek, T. Womack, G. Bricogne, Data processing and analysis with the autoPROC toolbox, Acta Crystallogr. Sect. D Biol. Crystallogr. 67 (2011) 293-302.

[44] A.J. McCoy, R.W. Grosse-Kunstleve, P.D. Adams, M.D. Winn, L.C. Storoni, R.J. Read, Phaser crystallographic software, J. Appl. Crystallogr. 40 (2007) 658-674.

[45] G. Bricogne, E. Blanc, M. Brandl, C. Flensburg, P. Keller, W. Paciorek, P. Roversi, A. Sharff, O.S. Smart, C. Vonrhein, T.O. Womack, BUSTER Version 2.10.3, Global Phasing Ltd, Cambridge, United Kingdom, 2017.

[46] F.L. Rock, W.M. Mao, A. Yaremchuk, M. Tukalo, T. Crepin, H.C. Zhou, Y.K. Zhang, V. Hernandez, T. Akama, S.J. Baker, J.J. Plattner, L. Shapiro, S.A. Martinis, S.J. Benkovic, S. Cusack, M.R.K. Alley, An antifungal agent inhibits an 
aminoacyl-tRNA synthetase by trapping tRNA in the editing site, Science 316 (2007) 1759-1761.

[47] J. Symersky, Y. Devedjiev, K. Moore, C. Brouillette, L. DeLucas, NH3-dependent $\mathrm{NAD}(+)$ synthetase from Bacillus subtilis at 1 angstrom resolution, Acta Crystallogr. Sect. D Biol. Crystallogr. 58 (2002) 1138-1146.

[48] M.L. Kuhn, E. Alexander, G. Minasov, H.J. Page, Z. Warwrzak, L. Shuvalova, K.J. Flores, D.J. Wilson, C. Shi, C.C. Aldrich, W.F. Anderson, Structure of the essential mtb FadD32 enzyme: a promising drug target for treating tuberculosis, ACS Infect. Dis. 2 (2016) 579-591.
[49] S. Schmelz, C.H. Botting, L.J. Song, N.F. Kadi, G.L. Challis, J.H. Naismith, Structural basis for acyl acceptor specificity in the achromobactin biosynthetic enzyme AcsD, J. Mol. Biol. 412 (2011) 495-504

[50] E. Harder, W. Damm, J. Maple, C.J. Wu, M. Reboul, J.Y. Xiang, L.L. Wang, D. Lupyan, M.K. Dahlgren, J.L. Knight, J.W. Kaus, D.S. Cerutti, G. Krilov, W.L. Jorgensen, R. Abel, R.A. Friesner, OPLS3: a force field providing broad coverage of drug-like small molecules and proteins, J. Chem. Theory Comput. 12 (2016) 281-296. 